Portland State University

PDXScholar

Spring 7-5-2018

\title{
An Experimental Study on the Impact of Informal Rape Myth Education to Alter Rape Myth Acceptance Scores in a Non-Student Sample
}

Leah Noelle Reddy

Portland State University

Follow this and additional works at: https://pdxscholar.library.pdx.edu/open_access_etds

Part of the Criminology and Criminal Justice Commons

Let us know how access to this document benefits you.

\section{Recommended Citation}

Reddy, Leah Noelle, "An Experimental Study on the Impact of Informal Rape Myth Education to Alter Rape Myth Acceptance Scores in a Non-Student Sample" (2018). Dissertations and Theses. Paper 4460. https://doi.org/10.15760/etd.6344

This Thesis is brought to you for free and open access. It has been accepted for inclusion in Dissertations and Theses by an authorized administrator of PDXScholar. Please contact us if we can make this document more accessible: pdxscholar@pdx.edu. 
An Experimental Study on the Impact of Informal Rape Myth Education to Alter Rape Myth Acceptance Scores in a Non-Student Sample

by

Leah Noelle Reddy

A thesis submitted in partial fulfillment of the requirements for the degree of

\author{
Master of Science \\ in \\ Criminology and Criminal Justice
}

Thesis Committee:

Christopher Campbell, Chair

Kelsey Henderson

Kathryn Wuschke

Portland State University 2018 


\begin{abstract}
Sexual assault has come to the forefront in terms of prevention and education for many social institutions such as college campuses. However, with a growing body of research highlighting the importance and effectiveness of interventions, research examining the impact of rape related education on altering rape myth acceptance (RMA) among nonstudent populations is severely lacking. This is a problematic gap given the issue of sexual assault in the United States extends well beyond academia. The current study aimed to fill this gap by employing an experimental design with repeated measures. To detect changes in RMA after a short rape myth education intervention, pretest and posttest RMA scores were generated for all participants by using an altered version of the Updated Illinois Rape Myth Adherence scale (McMahon \& Farmer, 2011). A sample of 137 non-students were surveyed via Amazon's Mechanical Turk and randomly assigned to a treatment (educational intervention) or control (unrelated video content). The treatment video was roughly ten minutes in length and constructed by the author for the purpose of the current research, after a search for a similar informal and accessible, but still research based, video was not successful. Participants were presented with common rape myths and then provided with information (e.g., accessible research/statistics) with the aim to "debunk" these myths, and ultimately decrease acceptance of myths. Analyses indicate support for a significant change in RMA score from pretest to posttest in the treatment group, finding support for the use of informal rape myth education in altering immediate RMA scores of a non-student sample. RMA scores were also examined by demographics to determine if within group differences were present in the sample. No
\end{abstract}


consistent results emerged in both the treatment and control group. Limitations and implications for future research are discussed 


\section{Acknowledgments}

Possibly one of the hardest parts of finishing this thesis project is trying to find the "right" words to express my level of gratitude for all the people who helped me throughout this process. I am grateful for the commitment, patience, understanding, and support of so many individuals who made this possible.

First and foremost, I would like to acknowledge my thesis chair and advisor, Dr. Chris Campbell. The gratitude I hold for your plethora of guidance and support throughout this process/program is immeasurable. Thank you for allowing me to grow, helping me succeed, and always knowing when and how to ground me when I needed it most.

I would also like to thank the remainder of my committee, Dr. Kelsey Henderson and Dr. Katie Wuschke, for your invaluable input throughout this process. You have improved the quality of this project tremendously. Kelsey, a special extended thank you for guiding me through the process and woes of experimental research.

Beyond faculty, I am indebted to the Criminology and Criminal Justice program, for introducing me to my cohort members, and some of the greatest people I know. Kayla LaBranche, Chris Dollar, Alec Thompson, Tanika, Siscoe, and Molly Harvis, each one of you has offered support, friendship, and much needed humor throughout this program. I am grateful to have gotten to know all of you. (Also, thank you for all the dog pictures you've sent over the last two years.)

Kayla and Chris, my thesis family, you deserve a special recognition for your part in this process. I truly could not have done this without the two of you. Thank you, and 
congratulations to you both for making it through the late nights and endless stress in order to create remarkable theses.

Finally, I would like to thank my mom, Christine. Your faith in me has never wavered. I could not be where I am today without your love and support that has always urged me on. Thank you. 


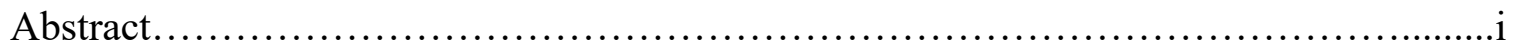

Acknowledgments ...........................................................

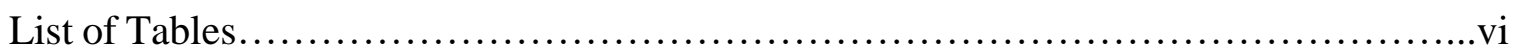

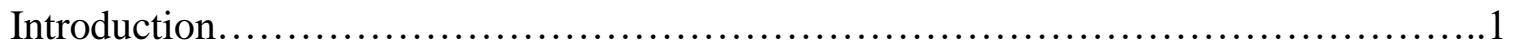

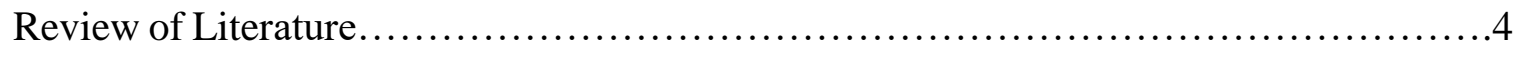

Methods................................................................ 20

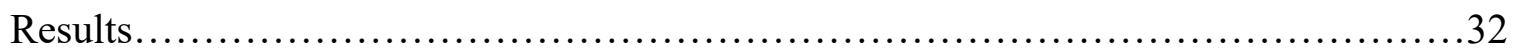

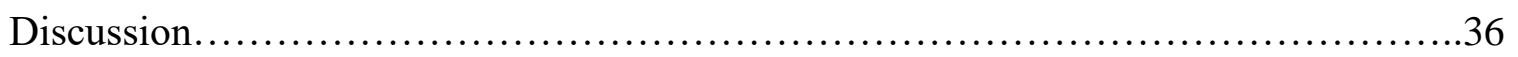

Conclusion............................................................44

References...........................................................45

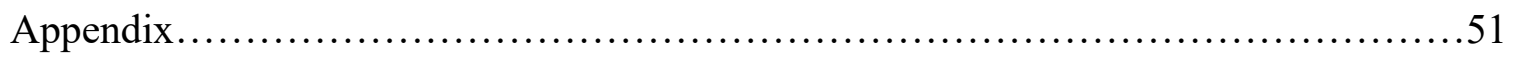

Appendix A: RMA Survey Items...........................................51

Appendix B: Video Script.............................................52

Appendix C: Changes in Measure Post Intervention............................56

Appendix D: RMA Score Differences by Demographics, Full Scale.............57

Appendix E: RMA Score Differences by Demographics, AFI..................58

Appendix F: RMA Score Differences by Demographics, TL.................59

Appendix G: RMA Score Differences by Demographics, WRR...............60

Appendix H: RMA Score Differences by Demographics, DMT...............61

Appendix I: RMA Score Differences by Demographics, DMT-I...............62

Appendix J: Correlations Between Age and RMA, Control Group..............63

Appendix K: Correlations Between Age and RMA, Treatment Group.............64 


\section{List of Tables}

Table 2: Demographic Differences Between Groups................................29 


\section{Introduction}

College campuses have been continuously and notoriously documented as housing high prevalence of sexual assault (Fisher, Daigle, \& Cullen, 2010). A longstanding statistic has characterized this problem by noting 1 in 4 women experience attempted or completed rape during their college career (Koss et al.,1987; Campus Climate Survey on Sexual Assault and Sexual, 2015). Furthermore, within the general population, research has estimated 1 in 5 women and 1 in 71 men in the United States are victims of rape or attempted rape (Black et al., 2011). However, research has also indicated that definitional, methodological, and reporting issues make constructing an accurate sexual assault prevalence rate difficult (Kruttschnitt, Kalsbeek, \& House, 2014). Thus, the 1 in 4 rate, as well as others alike (e.g., the Black et al., 2011 statistics), should be taken with a grain of salt, as the true rate is unknown. Nonetheless, these high prevalence estimates are indicators of an issue requiring further attention. As literature has suggested a connection between acceptance of rape myths and rape proclivity (Bohner et al., 1998; Chiroro, Bohner, Tendayi Viki, \& Jarvis, 2004), the focus of this study then pertains to topics of acceptance and examining a possible intervention to decrease it.

Though definitions of rape myths vary, they can be broadly defined as largely inaccurate and culturally prescribed beliefs about rape, typically including elements of victim blaming and offender absolution, which ultimately reinforce favorable perceptions of sexual aggression (Burt, 1980; Lonsway \& Fitzgerald, 1994; McMahon \& Farmer, 2011). Within the overarching concept of rape myths, distinct domains of subcategories (e.g., the victim was asking for it; the perpetrator did not mean to) also exist. 
Subcategories may be indicative of the many functions rape myths serve, such as justification for dismissal of incident, protection of belief in a just world, and the continued control and oppression of women (Lonsway \& Fitzgerald, 1994). Rape myth acceptance (RMA), refers to the degree to which an individual believes these rape myths, where scores are a numeric indication of an individual's adherence to such myths.

Lonsway and Fitzgerald (1994) have noted rape myths as being widespread, consistent, and capable of trivializing sexual assault. As such, research on altering RMA scores has become popular. Within this, one solution scholars have suggested might help combat rape myths, and ultimately decrease prevalence, has been to educate people on these myths with an aim to lower acceptance. Such educational programs are often formal and wide reaching in their content criteria and overall goals. The majority of these programs, and influence on RMA levels, have been implemented and empirically examined on college student populations, with a few conducted on high school students. Research on educating non-student populations to see if this can alter RMA scores is severely lacking.

While belief in myths has important implications with behavior, the impacts of myth adherence extend well beyond direct individual action. For instance, evidence of RMA effects within a broader legal context (e.g., of police and courts; see Edwards, Turchik, Dardis, Reynolds \& Gidycz, 2011), as well as having a potential impact on the willingness of survivor reporting (see Sable, Danis, Mauzy, \& Gallagher, 2010), have been found. Thus, considering the widespread impacts, finding interventions that vary in size and scope to influence RMA scores (i.e., beyond formal university programs) would 
be greatly beneficial. After all, rape is an issue on a societal level and not just in academia.

Subsequently, the primary goal of this study is to expand RMA research by examining the immediate impact of informal rape myth education among non-student populations. Using a simple pretest/posttest randomized control experiment, this study will test if informal rape myth education can promote change in participant RMA scores. Furthermore, this research proposes an examination of demographic variables in relation to RMA scores, where extant literature has suggested particular demographic variables may be influential in RMA. 


\section{Review of the literature}

\section{RMA conceptualization and measurement}

Considering the known links between rape attitudes and proclivity (Bohner et al., 1998; Chiroro, Bohner, Tendayi Viki, \& Jarvis, 2004), paired with perpetually high rates of sexual assault, understanding RMA is crucial. Thus, a wide range of research with the aim to determine levels of RMA has been conducted. Extant research has employed a variety of survey instruments to generate scores indicative of RMA, though none have been as heavily relied upon as the Rape Myth Acceptance Scale (RMAS) (Edwards et al., 2011). Constructed by Burt in 1980, this scale was created to fill substantial gaps in rape myth research. Burt observed that much of the existing work was atheoretical, and yet still attempted to incorporate a mix of cultural stereotypes into research. Further, the research had been conducted using inconsistent definitions. To address these gaps, Burt defined rape myths as "prejudicial, stereotyped, or false beliefs about rape, rape victims, and rapists" (p. 217). Using this definition, Burt created and empirically tested an acceptance scale that incorporated social psychological, feminist theory, and demographic factors for the first time. The measure was constructed by surveying a sample of 598 adults in Minnesota, via random selection of households. Burt's study resulted in a 19-item scale that could be used to generate a casual model of critical factors related to RMA. Burt (1980) concluded that factors such as adherence to traditional gender roles, acceptance of interpersonal violence, and distrust of the opposite sex were predictive of RMA. A 7-point Likert scale is used to measure Burt's RMA items. 
Though Burt's scale is still commonly used, the Illinois Rape Myth Acceptance (IRMA) scale has also been frequently employed since its formation. This scale was created by Payne, Lonsway and Fitzgerald in 1999 due to a multitude issues identified with the RMAS in earlier work. Some of these issues included non-robust and inconsistent findings outside of gender, a largely under studied structure, not being based in a theoretically sound definition of rape myths, lacking domain breakdowns, and being too heavily linked to hostility towards women, rather than directly focused on rape myths (Lonsway \& Fitzgerald, 1994; Lonsway and Fitzgerald, 1995). To address the definitional issue, the creators of this scale conceptualized rape myths as "attitudes and beliefs that are generally false but are widely and persistently held, and that serve deny and justify male sexual aggression against women" (Lonsway \& Fitzgerald, p. 134, 1994). To address the lack of domains and overreliance of hostility towards women, efforts were directed with an aim to group myth items in comprehensive domains. A new set of 95 rape myth items were presented to 604 university students, where items were later divided into subscales of myths, and their structure was tested. Six studies encompassed the entire construction process of IRMA.

The final IRMA consists of a 45-item survey, including a single factor scale of overall RMA, but also includes seven subscales of rape myth domains. Subscales consist of "she asked for it", "it wasn't really rape", "he didn't mean to ", "she wanted it", "rape is a trivial event", and "rape is a deviant event". This measure also uses a seven-point Likert scale. Recognizing that a 45-item scale may be excessive for some research (e.g., time constraints, survey fatigue), the authors (Payne, Lonsway\& Fitzgerald, 1999) also 
created the IRMA short form (IRMA-SF) scale. An adjusted scale was created by taking the top components of the IRMA and condensing them into a 20-item measure.

In 2011, McMahon and Farmer constructed an updated IRMA scale (U-IRMA). The creators of this instrument chose to use a more encompassing definition of rape myths than Payne, Lonsway, and Fitzgerald (1999) in their measure. McMahon and Farmer state rape myths are "false beliefs about rape shaped by sexism and other prejudices individuals hold" (2011, p. 71). The authors created this measure largely to overcome potential language issues they identified in the original IRMA, if trying to detect covert and subtle rape myths. This scale is largely focused on identifying myths related to victim blaming, as well as considers aspects of offender absolution. This was also a multi-phase study. Stage one involved three different focus groups. Two of these groups employed undergraduate students involved in peer education of sexual assault, while the other consisted of campus professionals who deal with sexual violence frequently. Individuals in these samples were asked to review the IRMA, and consider the type of language used by students when speaking about sexual violence. IRMA scale items were then updated accordingly. Stage two involved the psychometric testing of the scale on 951 undergraduate students. Analyses revealed five distinct subscales among 19 items, resulting in the removal of subscales about rape being deviant/trivial, and victims "wanting" to be raped, from the original IRMA. However, the authors did add a subscale about perpetrators not meaning to be an offender, specifically when intoxicated.

As this U-IRMA scale is the most up to date and well validated measure at present, it is the scale used in this study. However, this is not the only reason for using 
the U-IRMA. The comprehensive definition of rape myths employed for this scale (which others may lack), as well as the use of culturally relevant language aimed to detect covert rape myths, are also reasons of influence. Further, the length of the instrument, while still deeming analysis of subscales appropriate, makes the U-IRMA a suitable choice for the current research.

\section{Prevention training and education}

Research on RMA scores has traditionally been conducted on student populations. This is partially driven by policy actions in lieu of the previously mentioned 1-in-4 statistic on higher education campuses. With the continued emphasis on this statistic, federally funded universities are now mandated to require students take part in sexual assault prevention programs (Campus Sexual Violence Elimination Act, 2013). According to the Culture of Respect, a website devoted to sexual violence prevention on campuses, 37 such programs exist across the country (2017). Most of these programs are evidence-based as they pertain to behavioral outcomes (i.e., sexual assault), and many of them target rape myths in some capacity. The mandatory nature of these programs on college campuses has created a need for evaluation, which is why much of the current literature on altering RMA scores has been conducted on the readily available student population. Research gathering data from the non-student population on altering RMA scores via intervention appears to be limited to further specialized populations, such as law enforcement and military personnel. Research on the general population (i.e., nonstudent samples) as a whole is nearly nonexistent, with only one community-based study 
on lowering RMA known to the researcher, at present (see, Community Action Strategies to Stop Rape, 1980).

Within college student populations, many studies have found general support for sexual assault programs in altering RMA scores. A meta-analysis conducted in 2005 by Anderson and Whiston examined a mix of 69 published and unpublished studies on college students, ranging from 1978 to 2004 ( $n=18,000+)$. RMA change was among one of the many components considered in their analysis. The aim of the study was to judge overall effectiveness of interventions, and thus only included those studies which employed controlled pre/posttest designs. Overall, the authors found the change in rape attitudes garnered an average effect size (Cohen's d) of .21, suggesting programs have a small impact on rape myths.

A more recent meta-analysis conducted in 2013 by Katz and Moore examined the effectiveness of bystander sexual violence education programs in college students. Similar to Anderson and Whiston, the authors reviewed only studies including pretest and posttests, on a number of variables, one of which included rape myth attitudes/myths. Ranging from 1997 to 2011, twelve studies were included with this criterion. To be included, studies had to be conducted on in-person bystander training programs aimed to reduce personal risk of victimization, and increase response to events. Some of these programs included: Bringing in the Bystander, The Men's Program, and The Men's Project. The authors reported small effect sizes (between .21 and .36) in support of decreasing RMA with the presence of a program, post intervention. 
Looking at specific programs, one widely implemented curriculum within higher education is the bystander intervention program known as Green Dot. Green Dot aims to target university students and members to react in high-risk situations, rather than remain inactive bystanders. Sexual assault is one of the scenarios included. Coker and colleagues (2011), conducted a large-scale review $(n=2,504)$ of this program. While this program does not directly address the issue of rape myths in its context, RMA scores were collected. Analyses indicated study participants who had received the Green Dot training had significantly lower adherence to rape myths in comparison to those who did not receive training, deeming it successful in altering scores. A decrease in scores, despite lacking direct RMA intervention may further support Burt's (1980) claim that the concept of rape myths are ingrained in a multitude of attitudinal variables (e.g., sex role stereotyping), and should thus be targeted through a variety of means (e.g., using feminist ideology to challenge sex role stereotyping).

Given the general support for successfully lowering RMA in student populations through formal educational programs, the next logical step is to consider how this may be applied to non-student populations, in an effort to achieve the same result. A review of the relevant literature reveals mixed findings in the success of lowering RMA in nonstudent samples. In a three-year longitudinal study conducted on a community level in Columbus, Ohio, promising results emerged (Community Action Strategies to Stop Rape, 1980).This study, conducted by Women Against Rape employed a quasi-experimental time-series design. The researchers gathered pretest RMA scores, offered four different interventions, and then conducted multiple follow up surveys inquiring about RMA. 
These interventions included: "a series of women's rape prevention workshops ... a Whistle Alert program; a Shelter House program; and a Women's Rape Prevention Network" (p. 238), thus suggesting a mixed approach, where tackling RMA was just one of the many components of this study. Among the results of this study, the researchers found a significant decrease in RMA post interventions, compared to a random sample of community members who were also surveyed. While this study garnered promising results for community level without focusing on a specialized population (e.g., law enforcement officers), a review of American literature suggests no other programs with empirical evaluation have been conducted since this 1980 publication.

In further support of education in non-student sample in altering RMA is a study conducted on men in the United States Navy $(n=1,505)$ using a repeated measures design (Terri et al., 2010a). Terri and colleagues found the educational intervention implemented to result in a significant decrease in RMA scores for the sample. When the same researchers later examined women in the Navy $(n=550)$ using the same intervention though, the intervention was not successful in significantly decreasing RMA scores (2010b). Similar non-significant changes from pretest to posttest measures were also found in a study conducted on law enforcement recruits $(n=161)$ (Lonsway, Welch, \& Fitzgerald, 2001). This research systemically studied the impact of officer sexual assault response training on both behavior (e.g., victim response) and attitudinal variables (e.g., rape myths) for the first time. While training improved behavioral responses, changes in RMA were not detected. Results were not examined through the lens of gender in the officer training study. 
The mixed findings noted above suggest that continued research on altering RMA in non-student samples is needed. This seems particularly so when the general success of formal programs on university students is taken into consideration. Further, bearing in mind that the majority of the research conducted on non-student samples noted here was completed on "specialized" populations, it is fair to argue the study of RMA change in a less specialized sample is warranted.

\section{Demographics and RMA}

One aspect which has been studied extensively within both student and nonstudent studies is the relationship between RMA and demographics. Extant research has suggested particular demographics may be related to RMA scores at an aggregate level (Johnson, Kuck, and Schander, 1997). This simply suggests that when levels of adherence to rape myths are studied and broken down by areas such as gender, differences in acceptance may be detected within groups (1997). Research has placed an emphasis on gender, race, and age, though other demographic variables have also been studied.

Gender. Undoubtedly, the most studied demographic variable in relation to RMA is gender. Such a focus on gender can be justified by the recognition that belief in rape myths may be closely related to other attitudinal variables, such as gender/sex roles and expectations. Understanding the socialization process differs by gender across societies, which may ultimately impact roles and expectations differently among genders, further justifies this (Johnson, Kuck, and Schander, 1997). Additionally, this is theoretically grounded in that the function of rape myths may differ by gender. For example, Lonsway 
and Fitzgerald (1995) have suggested rape myths may serve as a tool to justify incidence for men, while they may serve to deny similar vulnerability for women. That is not to say, however, that any particular function is exclusive to a gender though, as both men, women, and other positions on the gender spectrum can be perpetrators or victims of sexual assault. Nonetheless, the type and degree of myths acceptable could differ by gender, which thus warrants study of this demographic in both student and non-student populations.

Within North American student samples, there has been continuous support for the notion that men hold higher levels of adherence to rape myths, when compared to women (Johnson, Kuck, and Schander, 1997; Proto-Campise, Belknap, \& Wooldredge, 1998; Szymanski, Devlin, Chrisler \& Vyse, 1993; Vonderhaar \& Carmody, 2015). This has been further supported by a cross-national study conducted by Stephens and colleagues in 2016, which studied a large sample of university students $(n=637)$ from three countries (United States, Japan, and India). Like in the primarily North American studies, the authors found support that men held higher adherence scores than women in all three countries. This may suggest RMA and gender differences among college populations are not only present in Unites States, but may be more wide sweeping.

Within the general population (i.e., non-student populations), Feild (1978) also found support for men having higher acceptance of rape myths. Feild examined RMA through multiple populations within a single study, including citizens $(n=1,056)$, police, $(n=254)$, and convicted rapists $(n=20)$. Feild found that men in the citizen population and patrol officers held significantly higher adherence to rape myths compared to women 
in this group. All convicted rapists of the study were men, and thus a gender comparison was not possible for this sample.

Along similar lines, Smith, Wilkes, and Bouffard (2016) conducted a study on campus law enforcement officers. The sample of this study consisted of 92 men and 26 women. Significant differences in RMA scores by gender were not generated in this study, but the small and uneven breakdown by gender may have been influential to these results. Other research comparing individuals in the Military Academy $(n=1,169)$, Naval Academy $(n=1,916)$, and university Greek life members $(n=393)$ have found gender differences (Carroll, Rosenstein, Foubert, Clark, \& Korenman, 2016). Results of this study again concluded men had higher adherence than women respective to their group, for all samples. However, the authors also note that the men and women of the military academy had the closest aligned beliefs, compared to gender categories of other samples. Overall, research examining gender and RMA in student and non-student samples suggests a consistent divide, where men hold higher RMA than women.

Race. Race is another demographic domain to receive substantial attention. The initial justification for the inclusion of race as a possible factor in varying RMA seems largely arbitrary. Including race likely in an effort to account for all possible demographic variant influence on the RMA This may be guided and supported by the fact other related research has generated attitudinal differences by race (e.g., attitudes toward gender roles; see Blee \& Ticksmyer, 1995).

Within college samples, some research has demonstrated that when comparing racial categories by white and Black, Black participants have held significantly higher 
adherence (Giacopassi \& Dull, 1986; Johnson, Kuck, \& Schander, 1997). This is a finding that has also been generated within high school students (Proto-Campise, Belknap, \& Wooldredge, 1998). However, another study conducted by Carmody and Washington in 2001 did not find support for this. In fact, particularly when examining white women compared to Black women, white women held higher adherence scores, possibly suggesting differences at the intersection of race and gender. In a large study on college students $(n=979)$ examining RMA and race/ethnicity outside of the traditional white versus Black/nonwhite analyses, Vonderhaar and Carmody (2015) found further indications of significant racial differences. Particularly, they found Asian participants held higher adherence scores when compared to other racial categories. The authors gather this may be due to cultural differences, where some cultures may be more or less accepting of rape myths on an aggregate level.

Among non-student populations research on race and RMA has been sparse. However, Feild's (1978) previously noted study did find significant differences by racial category of participants in both the citizen and patrol officer populations. Similar to research that focused on student populations, the Feild study suggested that nonwhite participants in both populations had higher RMA adherence than white participants. In this same study, which also surveyed convicted rapists though, race, was not statistically significant (1978). It should be noted that the convicted rapist sample was extremely small. In the previously mentioned study on campus law enforcement, alike to gender, race was not significant (Smith, Wilkes, \& Bouffard, 2016). These mixed results leave the relationship between race and RMA (if one exists) largely unknown. 
Age. Another largely studied area of RMA is in relation to age. Within student populations, research has generated mixed findings on the relationship between age and adherence to rape myths. For example, some researchers found no significant differences in adherence by age (Carmody and Washington, 2001; Johnson, Kuck, \& Schander, 1997), while more recent research has found older participants had a lower RMA (Vonderhaar and Carmody, 2015). Non-student samples have also generated ambiguous findings. For example, in the portion of Feild's study on convicted rapists, there was a negative correlation between age and RMA scores, while the citizen and police RMA scores were generally unrelated to age. Burt's 1980 study conducted on the general public, however, found younger participants held lower RMA scores. To further the complexity of this relationship, Smith, Wilkes, and Bouffard's campus law enforcement study found no correlation of officer age and RMA (2016). Thus, age in relation to RMA appears largely inconsistent.

Other possible relationships. In the variation of demographic variables Burt (1980) examined relating to RMA within the general population, she also included education as a possible factor. Burt found education level was related to adherence level with higher education correlating with lower adherence. This finding was also supported in a recent study of university students (Vonderhaar \& Carmody, 2015), where lower class standing (e.g., freshman, sophomores) was related to higher adherence scores than that of more senior classes. Given these possible indications of difference in student populations, education level of non-student populations is important to consider. This is said as it could be that those with higher education (e.g., a bachelor's degree over a high 
school degree) could have lower RMA overall. Thus, considering education level, even in non-student samples, could be important in predicting RMA scores.

Aside from education, a preliminary study examining sexual orientation in relation to RMA was recently conducted (Schulze \& Koon-Magnin, 2017). This study consisted of a nationwide survey, which was one of the first of its kind, to consider sexuality on a widespread scale relating RMA scores. The authors found support for the concept of sexual orientation being impactful on a between heterosexual to nonheterosexual scale. Overall, non-heterosexual participants had lower RMA scores. Men, however, still maintained a higher adherence to myths than women, despite sexual orientation. It should be noted that while $35 \%$ of this sample was composed of nonstudents, offering the potential to widen the net of demographic study of RMA, this study only analyzed sexual orientation and gender in the context of scores. Race, age, education, and region were collected for this sample, but were not included in any statistical analysis comparing RMA scores, within this publication. Thus, while over $1 / 3$ of the sample was a non-student sample, demographic relationships to RMA by population subtype are left largely unknown. Considering the preliminary results of this study, more research on sexual orientation may be warranted.

\section{Gaps}

An examination of the current literature on RMA reflects a limitation it's in scope, primarily through the samples employed. This is evident in both RMA change research, and RMA demographic research. The limitation in sample demographics tend to be present in one of two ways. First, the majority of RMA research is conducted on 
university student samples, rather than non-student samples, that are better representative of greater society. Further, this narrowed focus is problematic in that these samples do not reach the issue of sexual assault on a societal level. Focusing on primarily student populations views rape and RMA only through the lens of campus sexual assault, largely disregarding the 1 in 5 and 1 in 71 statistics that exist outside of academia (Black et al., 2011).

Second, while research on non-student populations and RMA does exist, and has been presented here, much of this research is restrictive to "specialized populations" (e.g., law enforcement and military personnel). This is particularly present in RMA change research. To clarify, of the four RMA change studies on non-student samples examined here, only one of them took place in a general community setting, rather being conducted on law enforcement or military personnel. Further, this one non-specialized, non-student, quasi-experimental study was conducted in 1980 (Community Action Strategies to Stop Rape), and a current review of the literature did not reveal any studies of this scope, since. It would be a disservice to assume RMA attitudes in non-student populations have not changed since the 1980s, warranting the need for more current study. These limitations (e.g., primarily specialized populations or older research) are also present in demographic analysis and RMA for non-student samples. Of the studies on demographics considered here, those non-student, non-specialized, studies were mostly conducted prior to 1980 (i.e., Feild 1978; Burt, 1980). While the 2017 study examining sexual orientation and RMA (Schulze \& Koon-Magnin) employed a mixed student and non-student sample 
and collected demographics, the authors did not examine demographics outside of sexual orientation and gender.

While it is important to acknowledge this expansion of RMA research beyond student samples, it is also important to recognize the possible limitations of this research. For instance, examining RMA change via education in law enforcement/military can be telling about these specialized populations overall, but consideration of the possible differences of these samples in comparison to the population in a general sense (e.g., influence of police/military culture) is crucial. Consideration of these specialized populations and RMA is important, but examining change research in non-student populations primarily through this lens may still miss viewing sexual assault on a societal level. Essentially, this sort of analysis may not reach the general population, who could be on the forefront of a rape survivor's daily interaction, or even as jurors in a trial, should a case make it that far into the system. Thus, there is a need to fill current gaps in RMA research by studying both change in acceptance after intervention, and demographics and scores, through a less specialized, non-student, sample.

\section{Current Study}

The current study aims to help fill these gaps in rape myth research. Accordingly, this study has two core research questions:

RQ1. To what extent can education on rape myths alter RMA scores among non-student participants?

RQ2. To what extent are demographic differences important in predicting baseline RMA scores? 
To address these questions, this study uses an experimental design on a non-student population to examine pre/posttest change in RMA scores, when given a short intervention designed to debunk rape myths. This research tests if informal rape myth education has an impact on changing RMA in a non-student sample. I hypothesize two general outcomes for this research.

$\mathrm{H}_{1}$. When presented with informal rape myth education, RMA scores will significantly decrease from pretest to posttest.

$\mathrm{H}_{2}$. In accordance with the literature, particular demographic variables (e.g., gender) will possess a significant relationship with RMA scores, while others (e.g., age, race) may not. 


\section{Sample}

\section{Methodology}

This study sample was obtained through the Amazon's online survey platform: Mechanical Turk (MTurk). MTurk gathered prospective participants and then redirected them to a Qualtrics page which held the survey, via an anonymous survey link. The final sample size consisted of 137 participants, who were randomly assigned to the treatment or control condition. The treatment condition contained 65 participants, while the control group had 72 participants. This study included minimal eligibility criteria, but required participants to live in the United States, as well as not be enrolled in higher education at the time of surveying, to be eligible. The exclusion of college students was to ensure the expansion of the non-student population. It is important to note research has suggested a minimum sample size for research similar to the current study of 788 to detect small effect sizes, while only needing 128 to detect moderate effects (Funder et al., 2014). Thus, given the sample size used, interpreting small effect sizes for this study would be inappropriate, and only moderate or larger are considered.

Administering the survey through MTurk allowed for a greater sample size with more age and location variation than the convenience a college campus could offer. Expanding the target population beyond university students allows for greater generalizability, and addresses the latter part of the proposed research regarding variation by demographics. Research on the demographics of MTurk workers has shown that workers tend to be younger, more educated, report higher levels of being liberal, and are unrepresentative of Blacks and Latinos, in comparison to the general population (Berinsky, Huber \& Lenz, 2017; Shapiro, Chandler \& Mueller, 2013). That is to say, MTurk workers do differ from the general population on an aggregate level, however, 
these samples may be more in line with the general population than in person surveys (Berinksy, Huber \& Lenz, 2017). Thus, this survey platform still has the potential to expand beyond the norm of surveying college populations (Crump, McDonnell, \& Gureckis, 2013). Further, the Mturk to Qualtrics platform has allowed for anonymous survey taking, where no identifying information, including IP addresses, was collected by Qualtrics, or available to the researcher via MTurk. Considering the arguably sensitive nature of this study, social desirability concerns (e.g., participants responding in a way they have deemed socially fit, rather than providing honest attitudes) are genuine in potentially impacting study validity.

\section{Procedure overview}

Once participants were recruited via MTurk, they were directed to a Qualtrics page containing the survey. The participants electronically signed a consent form regarding their anonymous participation in the study, the nature of the study, anticipated harms, and their choice to leave the study at any time. After confirming consent, respondents completed a short demographic section, among other independent measures of interest, described in further detail below. Participants were then presented with the RMA survey for the pretest.

Upon pre-test completion, individuals were randomly assigned to one of two conditions (i.e., treatment or control). If assigned to the treatment group, individuals received exposure to a short, informal educational video meant to debunk common rape myths, as targeted in the survey instrument. The control group did not receive this 
exposure, and instead watched a neutral video unrelated to the topic of the study ${ }^{1}$. Both videos were nearly 10 minutes in length.

The survey contained four attention check questions. Qualtrics automatically ended the survey for any participant who failed an attention check question. Participants in the treatment group were asked a small series of manipulation check questions pertaining to the content of the manipulation after completion. As the control group did not view of treatment video, they were not asked these manipulation check questions, and were instead given a short series of filler questions about their video to keep group tasks consistent.

An immediate posttest was then given to both groups. The posttest consisted of the same RMA items as the pretest, though questions were presented in a different order. After completion participants were thanked for their time. Participants who were not removed by Qualtrics for failing attention check questions were given a code to input into MTurk to receive compensation ${ }^{2}$. The researcher then reviewed time stamps provided by Qualtrics. Any participant who did not meet a 12-minute requirement was excluded from the study and marked to not receive compensation. A review of codes was then conducted and participants who met criteria were compensated. The 12-minute minimum was set as a means to ensure usable data, as surveys under 12 minutes long would suggest proper attention was not payed to the 10-minute video and several survey questions. Participants were warned of these criterion prior to the start of the survey, as well as the 12-minute requirement was reiterated on the video page of the survey.

\footnotetext{
${ }^{1}$ The topic of the control group's video was on ten "interesting" weather phenomenon's that have been video recorded.

${ }^{2}$ Participants were compensated $\$ 2.00$ each.
} 
A total of 231 MTurkers attempted to participate in the study, where only 151 were able to complete the study in passing exclusion criteria (e.g., non-student, over 18), and all attention questions. MTurk automatically removed the 80 cases who failed these, with the majority of removals being due to participants indicating they were currently enrolled in higher education. Further, of this 151,10 were removed from the study and not compensated for being below the 12-minute threshold. Further, while compensated, 4 participants were removed from the data for failing to correctly answer 2 or more of the manipulation check questions in the treatment group, resulting in a final useable sample of 137.

\section{Measures}

Dependent variable. The dependent measures of this study were RMA scores generated. These scores were generated by administering an adapted 19 item-version of the Updated Illinois Rape Myth Adherence (U-IRMA) scale (McMahon \& Farmer, 2011). As previously stated, this measure covers domains of "she lied", "he didn't mean to", "he didn't mean to (intoxicated)", "she asked for it", and "it wasn't really rape". For the purpose of this study, these domains were altered to be gender neutral, in recognition that gender does not exclude perpetration or victimization of sexual assault. For example, where a domain was worded as "she asked for it", the domain was altered to state "they [the victimized party] asked for it". In line with this, the survey questions themselves were slightly altered to include gender neutral pronouns, where, for example, in a statement which previously said, “if a girl doesn't physically resist even if protesting verbally it can’t be considered rape" was changed to "if a person doesn't physically resist even if protesting verbally it can't be considered rape". The five domains consisted of "asked for it" (AFI), 
"they lied" (TL), "was not really rape" (WRR), "did not mean to" (DMT), and "did not mean to - intoxicated" (DMT-I).

This measure employed a six-point scale Likert scale from 1 (being strongly disagree) to six (being strongly agree). Unlike previous uses of this measures, no neutral option was offered to participants. This was used as a protection against chronic fence sitters on such sensitive topics that are susceptible to social desirability, and therefore this study used a forced-choice. See Appendix A for a complete breakdown of the scale items.

RMA scores were produced for each participant in the pretest and posttest regardless of assigned condition. These scores were composite, generated from adding up level of adherence to each item in the scale (from 1 to 6). These were then averaged for each person to generate a similarly interpreted mean score, which could range from 1 to 6 . Higher scores represent higher acceptance of rape myths (see below for corresponding alphas).

This research also generated mean scores for individuals by subcategories of myth, in the same manner as the full-scale model. Factor analysis was conducted prior to any additional statistical analysis to test factor structure of the RMA measure used, as well as construct validity and reliability (alpha) measures. This was to ensure the scales used were suitable, and that the items used on the U-IRMA survey instrument were internally consistent.

Principal axis factoring (PAF) - best used on non-normal data - was conducted. Regarding the full-scale model, this generated a Kaiser-Meyer-Olkin (KMO) score of .9, which has been considered "superb", signaling adequate sample size to conduct factor analysis (Field, 2009). Bartlett's test of sphericity was significant a $<.001$, indicating that 
item correlations were large enough to conduct PAF. The Eigenvalue for the full model was -9.4 , well above Kaiser's criteria of 1 , and explained $49.2 \%$ of the total variance. PAF using Oblimin rotation on the subscales found support for the five-factor model proposed by McMahon and Farmer (2011), with an overall KMO of .903, and sphericity of $<.001$. All individual KMOs were $>.78$, which is above the .5 standard suggested by Field (2009). The total variance explained by the measure when broken into subscales was $68 \%$. The Eigenvalues for the first four factors ranged between 9.35 and 1, however the fifth factor only reached a score of .904 .

Though the fifth factor's Eigenvalue fell below Kaiser's threshold of one 1, factor analysis literature has suggested that this threshold to determine factor retainment may be "among the least accurate methods" (Costello \& Osborne, 2005, p. 2), and to consider the construct through context of other statistical tests, such as scree plots, and personal judgment in determination. Thus, a scree plot was also inspected, where the interpretation found support for a five-factor model before the tapering off of the line. Though three items were questionable in that they did not load into their "correct" factor, at the traditional cut off level above .32 (Tabachnick \& Fidell, 2001), they are theoretically sound, and thus remained in the data for analysis. Implications of these loadings are discussed further in the "discussion" portion of this work.

Regarding reliability, standardized alphas were constructed for the single model factor, as well as each of the subscales in the five-factor model. For the full scale, (Cronbach's $\alpha=.94$ ) item loadings ranged between .5 and .83 . In examining the subscales, the "they lied" scale $(\alpha=.92)$ contained item loadings ranging between .72 and .89. The "asked for it" factor $(\alpha=.89)$ loaded between a range between .7 and .77 . The 
"was not really rape" scale $(\alpha=.83)$ resulted in a range of .59 to .76 . "Did not mean to" $(\alpha=.86)$ generated a with a range between .63 and .77 , and "Did not mean to intoxicated" ( $\alpha=.68)$ had items falling at between .4 and .55 . Though the DMT-I alpha falls slightly below the normal .7 standard, it is consistent with the lower reliability for this factor found in the McMahon and Farmer (2011) study in constructing their scale ( $\alpha$ $=.64)$. The original U-IRMA generated $\alpha$ for these scales range from .64 to .82 , thus the results here are slightly higher.

\section{Independent variables.}

Primary. The primary independent variable for this study was the exposure to the educational rape myth manipulation (treatment). Participants either received the education (1) or did not receive the education (0).

It is pertinent to note that because this study was focusing on the general population, the education manipulation did not consist of any formal, sexual violence education programs utilized by universities. This is deliberate, as to expect a non-student population to consistently participate in such programs to gain information on rape culture is impractical. Such programs may be costly and time consuming. Moreover, they tend to primarily target sexual assault awareness and reaction, with a slimmer focus on actual rape myths. In fact, 24\% of these programs do not focus on rape myths at all (Culture of Respect, 2017).

The study instead utilized what appears to be a growing use of social media platforms as a form of informal education on a myriad of issues, including general health, travel, social justice movements, and politics. Some social media sites used in this non- 
traditional education include: Facebook, Twitter, Tumblr, and Youtube. The study aimed to keep the social media reliance in mind for the manipulation, where individuals were exposed to a relatively short video constructed for the purpose of this project. The aim was to construct a video somewhat similar to what may be found on social media sites, albeit this video was longer than what can typically be observed, outside of say, TedTalks, as it was nearly ten minutes in length.

This video was constructed with the aim to inform viewers of definitions of sexual assault, rape, consent, rape myths, and about rape myths and the realities of rape myths. Viewers were first presented a common rape myth, and then provided research and accessible statistics which suggest why the myth is inaccurate, aiming to effectively "debunk" the myth for the viewer. This consisted of six individual rape myths, which aimed to target aspects of the major rape myth domains covered in the survey instrument (i.e., "they didn't mean to", "it wasn't really rape", and "they lied"), as well as some outside the scope of this particular instrument, though validated in other instruments studies (i.e., "rape is a trivial event" and "rape is a deviant event") (Payne, Lonsway \& Fitzgerald, 1999). The video then concluded with bringing to light how persistence in rape myths may have adverse effects on a larger scope, such as effects found in the legal system (pertaining to legal justice) and effects to victims (pertaining to personal justice). The transcript for the created video can be found in Appendix B.

Secondary independent variables. Respondents were also asked to report on questions including: "Have you completed sexual assault prevention training previously? If so, did you feel it left a lasting impression?" and "If comfortable answering: have you, a close friend, or immediate family member, ever been a victim of a form of sexual assault?". 
The previous training question consisted of response options that included "yes, it had a lasting impression" (0), “yes, but it did not have a lasting impression (1), and "no, I have not had previous training" (3). This was ultimately coded in a dichotomous "no" (0), "yes" (1), variable, due to low counts when the 'yes' answer was divided. Over $80 \%$ of the sample had no prior sexual assault education. This question was asked, as consideration of baseline RMA scores could be influenced by prior education, where it could be theorized, based on extant literature suggesting success of programs in altering RMA, that these participants could have lower RMA scores compared to others. The victimization question (i.e., have you, a close friend, or immediate family member, ever been a victim of a form of sexual assault?") consisted of “yes" (0) or "no" (1) response options. Participants were reminded of the option to skip this question after given a warning that they may be presented a sensitive, and potentially triggering question. The data revealed that $45.3 \%$ of participants reported being previously victimized (vicariously or directly). This question was asked as the victimization status of participants could be influential in their attitudes toward rape and rape myths in general, and is thus an aspect that should be captured.

Demographic variables. To answer the second research question, a number of demographic variables were collected from survey participants. These measures included race/ethnicity, gender, sexual orientation, age, region, educational level, and political affiliation. Chi-square tables examining demographic groups did not generate significance, deeming randomization a success. A complete breakdown of the demographic variables can be found in Table 2 below.

Respondents were asked to report the race/ethnicity to which they most identify. Due to the lack of racial minorities participating in this study, race was ultimately 
dichotomized to white (0), and nonwhite (1). The sample was primarily white $(77.4 \%)$. Gender was presented as a drop-down menu of options, with an added option for a writein category. Participants only identified as men or women after time exclusions and failure of manipulation checks were applied, where a single gender fluid individual had to be removed. Women were coded as (1), and men as (0). The sample was evenly divided in gender. The question of sexual orientation allowed respondents to pick from several options, however, due to low percentages in variations, this variable was dichotomized as identifying as non-heterosexual (1), and heterosexual (2). In line with estimates in the general population (Gates, 2011), 10.2\% identified as non-heterosexual.

Table 2

Demographic Differences Between Groups

\begin{tabular}{|c|c|c|c|c|c|}
\hline \multirow[b]{2}{*}{ Variable } & \multicolumn{3}{|c|}{ Group \% } & \multirow[b]{2}{*}{$x^{2}$} & \multirow[b]{2}{*}{$P$} \\
\hline & Total & Control & Treatment & & \\
\hline Gender (Woman) & 49.64 & 50.00 & 49.20 & 0.01 & 0.93 \\
\hline Political Affiliation & & & & 0.30 & 0.96 \\
\hline Democrat & 42.34 & 40.28 & 44.62 & & \\
\hline Republican & 21.17 & 22.22 & 20.00 & & \\
\hline Independent & 33.58 & 34.72 & 32.31 & & \\
\hline Other & 2.92 & 2.78 & 3.08 & & \\
\hline Race (Non-white) & 22.63 & 19.50 & 26.10 & 0.88 & 0.35 \\
\hline Education ( $>$ Bachelor's degree) & 49.64 & 51.39 & 47.69 & 0.19 & 0.67 \\
\hline Sexual Orientation (Non-heterosexual) & 10.22 & 10.30 & 10.80 & 0.04 & 0.84 \\
\hline \multicolumn{6}{|l|}{ Age bracket } \\
\hline $18-29$ & 33.58 & 27.78 & 40.00 & 5.32 & 0.15 \\
\hline $30-39$ & 37.96 & 44.44 & 30.77 & & \\
\hline $40-49$ & 14.60 & 11.11 & 18.46 & & \\
\hline $50+$ & 13.87 & 16.67 & 13.85 & & \\
\hline Region & & & & 0.54 & 0.91 \\
\hline Northeast & 16.06 & 16.67 & 15.38 & & \\
\hline Midwest & 17.52 & 18.06 & 16.92 & & \\
\hline South & 44.53 & 41.67 & 47.69 & & \\
\hline West & 21.90 & 23.61 & 20.00 & & \\
\hline Prior Victimization & 45.26 & 43.06 & 47.69 & 0.23 & 0.63 \\
\hline
\end{tabular}


Age was captured by having participants report their birth year, resulting in a calculated continuous age measure. A bracketed age variable (e.g. 18-29, 30-39, etc.), was also constructed. The average age of participants was 36.2, with a range from 21 to 69 . The highest age bracket was 30-39 years of age (38\%). Respondents were also asked to check which state they reside in, this was then transformed into a region variable, in line with the census divisions, four region divisions (i.e., Northeast, Midwest, South, and West) were constructed. A political affiliation question offered options of Democrat (1), Republican (2), Independent (3), Other - specify (4), yielding the sample to be primarily democratic (42.3\%). Education was condensed in a dichotomous measure of having (1) or not having (0) a bachelor's degree or beyond. This was a near even divide in the sample.

\section{Analytical plan}

Prior to conducting analyses to answer RQ 1 and 2, a Mann Whitney $\mathrm{U}^{3}$ examining RMA scores was conducted to determine if there was a significant difference between the pre-tests of both the treatment and control group. This was to ensure there were no issues with distribution across conditions at the baseline RMA levels (e.g., removal for attentioncheck failure), in order to deem the groups comparable. The Mann Whitney $U$ was the appropriate test to use in order to account for the non-normal distribution of the data while comparing a continuous independent measure with a categorical dependent measure. A

\footnotetext{
${ }^{3}$ Due to a non-normal distribution of RMA scores, which remained after attempts of $\log , \log 10$, and square-root, the data was returned to its normal state and non-parametric analyses were conducted to examine the data.
} 
Mann Whitney $\mathrm{U}$ was then conducted on the posttests for the treatment and control, to determine if distribution of RMA scores by condition changed post intervention.

To answer RQ1, a testing of the intervention against RMA scores was conducted. This was meant to essentially ask: Did the informal education intervention work?. To test within-group changes, a Wilcoxon Signed Rank was conducted using the pretest and posttest scores, for both the treatment and control group. As there was a RMA score change observed within the treatment group, an examination of the posttest means between the treatment and control groups was also conducted. This was to know whether the observed change was due to the intervention, or some other spurious factor. By comparing the mean RMA scores from pretests and posttests, and between groups, this allowed for an experimental and reliable isolation of effects from the education manipulation. To further examine the RMA change from pre- to posttest by condition, linear regression (ANOVA) was conducted using the mean difference scores. This allowed for further parsing of the score changes post intervention.

Additionally, through RQ2, this study sought to examine RMA scores in the context of demographics, by assigned condition. Simply put, this was asking: Do different groups within a demographic variable hold varying levels of adherence? The type of tests conducted were dependent on the corresponding level of measurement of the given demographic test. These tests consisted of Mann Whitney U or Kruskal-Wallis for all categorical variables, while Spearman's correlation was used for the continuous age variable. Significant results would indicate if within group differences of demographics exist. 


\section{Results}

\section{RQ 1 - Testing the intervention}

The analytical test comparing pretests of the treatment group (median $[M]=2$, mean $[\mu]=2.13$, standard deviation $[\sigma]=.86)$ and pre-control group scores $(M=2, \mu=$ $2.04, \sigma=.85)$ was not significant, $(p=.57, z=-.57, r=.05)$. This suggests there were no issues with distribution across the conditions, allowing the data to be compared to each other and progression of analyses. The examination of posttest scores between treatment $(M=1.4, \mu=1.75, \sigma=.82)$ and control $(M=1.9, \mu=1.97, \sigma=.91)$ was also not statistically different $(p=.12, z=-1.5, r=-.13$ ). This suggests that distribution remained equal across the conditions post intervention.

Testing of the treatment group revealed RMA scores were significantly lower from the pretest to posttest $(p<.001, z=-5.94, r=-.51)$. An $r$ of this size indicates a large effect (Fields, 2009), and thus suggests a large difference in scores post intervention for the treatment group. Regarding the control group, interestingly, RMA scores were also significantly lower from the pretest to posttest $(p<.001, z=-3.46, r=-.30)$. This indicates a medium effect size, where there was still a substantial difference in scores after intervention, but it was not as pronounced as the difference in the treatment group. The analyses conducted on the distribution of difference of RMA scores from pretest to posttest (i.e., measuring the mathematical difference between the posttest score and the pretest score $)$, in the treatment $(M=-.26, \mu=-.38, \sigma=.43)$ to control $(M=-.05, \mu=-.07$, $\sigma=.17)$ was statistically significant at $(p=.001, z=-5.0, r=-.43)$. Characterized by a medium effect size, this suggests that though the pre to post RMA scores were significantly different from both conditions, there is also an unequal distribution of RMA 
difference means across conditions of treatment to control, where the treatment group has significantly higher changes in RMA scores. Almost every sub-factor also garnered a statistically significant difference, with TL, DMT, and DMT-I generating the largest effect sizes (see Appendix $\mathrm{C}$ for all scale breakdowns).

Linear regression was conducted using the difference (change) scores and condition, due to the ambiguity of the previous results (i.e., changes in RMA observed in both the treatment and control conditions). In this model, the treatment group is equal to one, where the constant represents the control group. Output revealed that receiving the intervention was a significant predictor of the change in RMA scores $(p<.001, t=-5.46$, $\left.\beta=-.425, \mathrm{R}^{2}=-.18,95 \% \mathrm{CI}[-.414,+.195]\right)$. This $\mathrm{R}^{2}$ suggests that $18 \%$ of the variance in the change can be attributed to the treatment group's manipulation. Further the standardized beta indicates that for every standard deviation increase in the intervention (i.e., presence), RMA scores are predicted to decrease by .425 standard deviations. The constant (control), was not significant $(p=.064)$. Therefore, the regression results indicate the treatment condition can be attributed to a significantly greater change in the RMA scores compared to that of the control condition. This concludes support for hypothesis 1.

\section{RQ 2- Examining demographics and RMA}

Six analyses were conducted on demographics, first with a single factor model which looks at all items in the scale used at once, and then by the five sub -factors (AFI, TL, WRR, DMT, and DMT-I). In total, there were six pretest mean scores per participant. These scores were compared to the demographics and other independent variables previously noted. These analyses were broken down by conditions of treatment and 
control. Only statistically significant results with at least a $p<.05$ are reported in text below. Full results for the single model in the five remaining sub-factor models can be found in appendices D through I.

Single factor model (full U-IRMA). The single factor model found only gender was significant in the treatment group $(p=.005)$, where women $(M=1.79, \mu=1.85, \sigma=$ $0.81)$ had lower scores than men $(M=2.47, \mu=2.41, \sigma=0.83, z=.28, r=.24)$. Within the control group, only having prior sexual assault education $(M=2.68, \mu=2,58, \sigma=$ $1.1)$ or $\operatorname{not}(M=1.94, \mu=1.93, \sigma=0.74)$ was significant, $(p=.035, z=2.11, r=.18)$, where those with prior education had higher RMA scores.

\section{Sub-factor models.}

$\boldsymbol{A F I}$. Gender was found significant for the treatment group $(p=.038)$, where women $(M=1.75, \mu=2.02, \sigma=1.22)$ had lower scores than men $(M=2.25, \mu 2.45, \sigma=$ $1.03, \mathrm{z}=2.07, r=.18)$.

TL. Gender was significant for the treatment group $(p=.005)$, where women $(M$ $=1.8, \mu=1.9, \sigma=.86)$ had lower scores than men $(M=2.4, \mu 2.49, \sigma=.87, \mathrm{z}=2.78, \mathrm{r}=$ .24). Also within the treatment group, political affiliation was significant $(p=.042)$ between self-identified Democrats $(M=1.8, \mu=1.9, \sigma=.79)$ and Republicans $(M=2.8, \mu$ $2.64, \sigma=.95, z=8.21)$.

$\boldsymbol{W R}$. Again, gender was significant in the treatment group $(p=.041)$, where women $(M=1.25, \mu=1.51, \sigma=.74)$ had lower scores than men $(M=1.75, \mu 1.86, \sigma=$ $.89, z=2.04, r=.17)$. Within the control group, victimization was significant, $(p=.039)$, where those who had victimization experience $(M=1, \mu=1.59, \sigma=.96)$ had lower 
adherence than those who did not report victimization $(M=1.5, \mu=1.77, \sigma=.7, z=2.06$, $r=.18)$.

DMT. Gender, again, was significant within the treatment group of DMT $(p=.001)$, where alike to the other sub-factors, women $(M=1.67, \mu=1.95, \sigma=1.08)$ had lower overall scores than men $(M=3, \mu=3.05, \sigma=1.39, z=3.21, r=.27)$. Having prior sexual assault education $(M=3.66, \mu=3.1, \sigma=1.32)$ yielded a significantly higher $(p=.008)$ overall RMA, compared to those who had not completed education $(M=2, \mu=2.03, \sigma=$ $1.06, z=2.63, r=.22)$.

DMT-I. In the control group, status of university education was significant, where those who reported having at least a bachelor's degree $(M=1,67, \mu=1.74, \sigma=.79)$ held significantly lower $(p=.015)$ RMA scores, compared to those with less than a bachelor's degree $(M=2, \mu=1.94, \sigma=.99, z=2.42, r=.2)$. Alike to the DMT sub-factor there were significant differences $(p=.01)$ between having prior sexual assault education $(M=$ $1,67, \mu=1.88, \sigma=.84)$ or $\operatorname{not}(M=2.33, \mu=2.54, \sigma=.92, z=2.5, r=.21)$, for the control group. Age as a bracket significant for the treatment group $(p=.046)$, between the $18-29(\mathrm{M}=2.5, \mu=2.5, \sigma=1.06)$ and $30-39(M=1.33, \mu=1.7, \sigma=.76, z=8.02)$.

No significant relationships were found for variables of race, sexual orientation. region, and age (as a continuous measure), in any of the factors examined. Further, as evident in the above written results, though significant results were generated for some variable across factors, none of the effect sizes calculated for these reached an appropriate threshold (moderate) which could allow the current research to capture with confidence, given the sample size. Thus, regarding RQ2 and $\mathrm{H}_{2}$, the answer remains largely unclear. 


\section{Discussion}

This study employed the use of a self-created, informal and informational video on rape myths, with the aim to "debunk" particular myths included, via presentation of accessible research and statistics. The video was constructed, as a search for an available preexisting video meeting desired criterion (i.e., relatively short, targeting strictly rape myths, and notation of resources) was unsuccessful. While at times arduous, this process resulted in the creation of a ten-minute final product that could be easily distributed to the non-student sample, and demonstrated to be somewhat successful in its mission. In sum, a combination of analyses indicate moderate success of the intervention in altering RMA scores of the treatment group. This offers preliminary support for informal sexual assault and rape myth education as having some ability to decrease rape accepting attitudes in a non-student population.

While studied with vigor on university students through formal programs, this is a facet of RMA change research which has been largely ignored on American non-student, non-specialized, populations. This is a troubling reality when we acknowledge the potential impacts rape myths may wield, in conjunction with the pervasive issue of sexual assault beyond academic settings. Therefore, while it is crucial to note this research can only conclude immediate alteration of rape attitudes within this sample, and not measure long-term effects, this study still offers invaluable insight into RMA change research. Thus, finding even some preliminary support for the immediate impact of education on non-student individuals in lowering acceptance of rape myths through the simple tenminute video used, which could spur future research in this understudied area, is exciting. 
In reviewing the relationships between demographics and RMA scores, despite prior analyses deeming randomization a success, this study yielded inconsistent results by condition. That is to say, no demographic variable was significant for both the treatment and control group, on any of the six scales. Even still, some interesting findings did emerge, with the most noteworthy being on five of the six scales, RMA differed significantly by gender. While the gender difference finding is consistent with prior research in that they all indicated men as holding higher RMA, this is a finding only generated in the treatment group, where the control group generally bared no difference. Further, where these significant gender differences were present, they only generated small effects, which the current study did not have enough power to adequately detect. Given the current state of the literature continuously finding gender differences, the lack of larger effect sizes (e.g., moderate or higher) was somewhat surprising. Whether these inconsistent and small effects are a symptom of the small sample size, or if there simply are not effects that large, is unclear. Considering the inconsistencies, no broad sweeping demographic conclusions can be drawn. It is theorized the mixed results between groups may be due to small sample sizes (treatment $n=65$, control $n=72$ ).

Overall, further research on non-student demographics and RMA scores is needed. Though results were ambiguous in the current research, a continued examination is justified, particularly if a continued attempt to implement education/programs in the general public is a goal. Further, if research does continue and demographic differences emerge on the whole or by domain, as they have in research on student populations, attention should be paid to these during implementation. For instance, if research concluded men consistently show higher adherence to a particular sub-factor, while 
women show a higher adherence to a different sub-factor, this would be an important piece of information to consider in the creation and implementation of interventions. Ultimately, acknowledging aggregate differences could allow for a more targeted approach, and thus possibly more successful interventions.

Additionally, though largely outside the scope of the research questions asked here, but pertaining to the realm of RMA research, a discussion of the U-IRMA scale used is warranted. As noted earlier, support for the five-factor model of the U-IRMA, presented by McMahon and Farmer (2011), was found through PAF using Oblimin rotation. However, throughout the factor analysis process, a four-factor model also produced promising results. The four-factor model would retain all items of the survey instrument, but would remove one of the sub-factors, placing those items in a different sub-factor. In the five-factor model presented by McMahon and Farmer, they had divided the domain of "[the perpetrator] didn't mean to" into perpetrator intoxicated and not intoxicated scales, as suggested by their factor analysis. Prior to their factor analysis, it was theorized that all of these DMT items would fall into one category. In the current study's PAF, however, the greatest support for division of DMT items does not lie in either of these options. Rather, factor loadings and pattern matrix suggests that removing the intoxication sub-factor and moving the intoxication into the "wasn't really rape" factor may be best.

In examining the DMT-I factors in question, it seems theoretically sound to suggest those items be included in WRR sub-factor. This is partially supported simply in how the items themselves are worded. To elaborate, these items consisted of "it shouldn't be considered rape if a person is drunk and didn't realize what they were doing" and "if 
both people are drunk it can't be rape". As evident in their wording these items do not imply, but plainly state, these actions should/do not constitute as rape, as is the aim of the WRR factor. After examination of the survey instrument, it is clear that aside from those in the WRR category, no other items make such an assertion, and it is unique to the WRR and DMT-I items. Thus, in their wording alone, though also supported theoretically, it is fair to argue for a combination of the WRR and DMT-I items. While this four-factor model would result in a slight decrease in total variance explained (-3\%), it could possibly increase in the integrity of the scale's sub-factors. This is a topic that should be further considered if the U-IRMA gains traction in the RMA research world.

\section{Limitations}

The findings from this study should also be interpreted in the context of its limitations, with the most prominent of these including issues of social desirability at both methodological and content levels. Given the sensitive nature of sexual assault and rape myth research, it would be a great disservice to ignore the potential influence of social desirability on study results. This is stated knowing prior literature has suggested that social desirability can contaminate research, particularly when considering research involving personal ethics (Fernandes \& Randall, 1992). Though an assurance of anonymity could be reasonably expected to decrease social desirability, the authors of the previously noted study also found that anonymity may not play large role in controlling for social desirability. Thus, even though this study was anonymous, this may not have successfully combatted social desirability.

Within the realm of RMA research, a study conducted in 1993 by Spohn examined RMA and social desirability under this assumption of the topic being 
controversial, which employed the Marlow-Crowne measure of social desirability. The study did not find a significant correlation between the two variables. It is important to recognize, however, this research only considered RMA scores and social desirability on a single measure, not within repeated measures research. It is reasonable to theorize that social desirability could be a larger threat in rape myth research when considering repeated measures, particularly when that repeated measure is immediate, such as in the current study. The immediate retesting of participants could have exacerbated the issue social desirability even further, and could possibly explain why a significant difference was found in both conditions.

Within the treatment group, social desirability could be explained through test retest bias within the context of participants being aware of the fact they are under observation, as well as what they're under observation for. This knowledge could influence participant responses, where they give responses they see as desirable to the researcher, or desirable to society as a whole. If participants were able to recognize the goal of this study was to detect an attitude change in RMA, where they are aware the intervention aimed to shift attitudes, it could have influenced their responses. Thus, there is a possibility the changes observed may be symptomatic of social bias, and not an indication of genuine attitude change. This is supported by the fact the regression model revealed only $18 \%$ of the variance in the RMA change can be attributed to the presence of the intervention, suggesting other factors (e.g., social desirability) may be influential in score alteration. When looking at the control group, the retest bias could also be impactful if participants had become aware they were part of the control group. Given a reasonable person could gather this based on the fact they did not receive an intervention 
video at all related to the survey instrument, which could result in participants becoming skeptical, and thus altering their scores, this is something to consider.

Suggesting the inclusion of the Marlow-Crowe scale of social desirability in future rape myth related research seems essential, particularly given this may not be an issue in just the current study, but in rape myth research in general. This is an issue supported by the knowledge that of the 69 studies included in Anderson and Whiston's 2005 meta-analysis of RMA change research, only 17\% of the studies included some sort of social desirability measure in their design. Considering the sensitive nature of rape myth research and the acknowledgement social desirability may be impactful on participant responses, it is fair to argue this a problem that needs to be addressed more consistently in future RMA research.

Pertaining to content issues and social desirability, it is important to consider possible impacts the current social climate may have on how individuals were willing to respond to study content. Prior to this study "going live", but after the onset of its idea, social and news media have been plagued with high profile accounts of sexual assault. As these are ongoing cases involving a number of well-established perpetrators (e.g., political figures, coaches, and television stars), these have been widely discussed on a variety of platforms. The revival of the "Me Too" movement ${ }^{4}$ via the emergence of its infamous social media hashtag and the large backlash it has received are evidence of this possibly adjusted social climate. This social climate could be impactful on individual's opinions, as well as what individuals think others believe their opinions should be. Thus,

\footnotetext{
${ }^{4}$ First developed in 2006, the Me Too movement is aimed at helping the healing process for survivors of
} sexual assault, particularly those in marginalized populations. 
people may be more inclined to respond to questions of sexual assault in a way they think is considered socially desirable/acceptable, rather than how they actually feel, given the current tensions. Considering data prior to this boom of sexual assault news was not gathered, this is all speculative, but is something to be considered.

Another limitation of the current study is the small sample size, which limits generalizability of findings. The small samples size could be more problematic for particular demographics analyzed in comparison to others (e.g., sexual orientation). Thus, when funding permits, future research on RMA in the general population should consider a substantially larger sample size. A larger sample size may address concerns of type II error, as well as statistical power and detection of small effects. It is important to note, however, that while this sample could not detect small effects, there was enough power to detect moderate effects. So, while the study is limited in its ability to adequately detect small effects, such as those possibly present in demographic analysis, moderate effects were detectable and present (i.e., pretest to posttest differences in RMA after intervention).

Finally, the design of this study is a limitation in two ways. First, it is a limitation in that it only included two time-points of comparison: a pretest and a posttest immediately following an intervention. As such, any changes in RMA detected in this study cannot be concluded as long-term or lasting effects, and rather, can only be considered through the lens of immediate impact on change. This study could have benefited from a greater number of collection points across a longer period of time, in line with the 34-day average wait period in RMA change research (Anderson \& Whiston, 2005). Second, as stated in the procedures section of the work, both the treatment group 
and control group did not receive the stated manipulation check questions. This could be an issue as it could generate false-positives. Additionally though, it could be argued that introducing these same manipulation check questions to the control group would have the potential to prime those participants. Given the already apparent potential issues of social desirability in this study, this exposure could have further exacerbated the finding of significant changes in the both groups post intervention. Despite the limitations noted here, this research has still provided a needed expansion of RMA change research in the much-needed section of non-student populations, while offering preliminary support for change via education. 


\section{Conclusion}

Overall, this study generated positive findings, where RMA scores were successfully altered in the treatment group post intervention. Meaning, acceptance of rape myths was decreased after providing information about rape myths. Regarding demographic differences, these remain largely unknown, and more research is needed. Future research should continue to consider testing sexual assault programs and changing RMA scores in the general population through an experimental design such as this. This could include looking directly at the type of programs currently being implemented in colleges, or through an informal lens, alike to this study. The latter may be of particular interest given the outburst of reliance on internet media as an informal educational resource. Ultimately, future research could employ improved methodology, with larger sample and multiple time points, to test the same concept of informal education here. This would allow for greater confidence in parsing out intervention impacts and demographic differences, as well as increasing variation in sample characteristics. No matter the avenue chosen though, if lowering prevalence rates of sexual assault is of true concern, this is research that needs to be conducted further, as a means to improve our knowledge of the public and RMA scores. This is said keeping in mind the links between RMA and rape proclivity, as well as the dispersed effects belief in these toxic myths have on the criminal justice system and American society as a whole. 


\section{References}

Anderson, L. A., \& Whiston, S. C. (2005). Sexual Assault Education Programs: A MetaAnalytic Examination of Their Effectiveness. Psychology of Women Quarterly, 29(4), 374-388.

Berinsky, A. J., Huber, G. A., \& Lenz, G. S. (2012). Evaluating Online Labor Markets for Experimental Research: Amazon.coms Mechanical Turk. Political Analysis,20(03), 351-368. doi:10.1093/pan/mpr057

Black, M.C., Basile, K.C., Breiding, M.J., Smith, S.G., Walters, M.L., Merrick, M.T., Chen, J., \& Stevens, M.R. (2011). The National Intimate Partner and Sexual Violence Survey (NISVS): 2010 Summary Report. Atlanta, GA: National Center for Injury Prevention and Control, Centers for Disease Control and Prevention.

Blee, Kathleen M., \& Tickamyer, Ann R. (1995). Racial Differences in Men's Attitudes about Women's Gender Roles. Journal of Marriage and the Family, 57(1), 21-30.

Bohner, G., Reinhard, M., Rutz, S., Sturm, S., Kerschbaum, B., \& Effler, D. (1998). Rape myths as neutralizing cognitions: Evidence for a causal impact of anti-victim attitudes on men's self-reported likelihood of raping. European Journal of Social Psychology, 28(2), 257-268.

Burt, M. (1980). Cultural myths and supports for rape. Journal of Personality and Social Psychology, 38(2), 217-230.

Cantor, D., Fisher, B., Chibnall, S., Townsend, R., Lee, H., Bruce, C., \& Thomas, G. (2015, September 21). AAU Climate Survey on Sexual Assault and Sexual Misconduct (2015). Retrieved from https://www.aau.edu/key-issues/aau-climatesurvey-sexual-assault-and-sexual-misconduct-2015 
Carmody, D. C., \& Washington, L. M. (2001). Rape Myth Acceptance Among College Women: The Impact of Race and Prior Victimization. Journal of Interpersonal Violence, 16(5), 424-436.

Carroll, M. H., Rosenstein, J. E., Foubert, J. D., Clark, M. D., \& Korenman, L. M. (2016). Rape Myth Acceptance: A Comparison of Military Service Academy and Civilian Fraternity and Sorority Students. Military Psychology,28(5), 306-317. doi:10.1037/mil0000113

Chiroro, P., Bohner, G., Viki, G. T., \& Jarvis, C. I. (2004). Rape Myth Acceptance and Rape Proclivity. Journal of Interpersonal Violence, 19(4), 427-442. doi: $10.1177 / 0886260503262081$

Coker, A. L., Fisher, B. S., Swan, S. S., Williams, C. M., Clear, E. R., \& Bush, H. M. (n.d.). Multi-Year Evaluation of "Green Dot" Bystander intervention on College Campuses. PsycEXTRA Dataset. doi:10.1037/e529382014-080

Community Action Strategies to Stop Rape. (1980). A Rape Prevention Program in an Urban Area. Signs: Journal of Women in Culture and Society,5(S3). doi:10.1086/495724

Crump, M. J., Gureckis, T. M., \& Mcdonnell, J. V. (n.d.). Can Internet Data be Trusted? Validating Mechanical Turk for Cognitive Research. PsycEXTRA Dataset. doi:10.1037/e502412013-957

Culture of Respect.(n.d.). Retrieved August 10th, 2017, from https://cultureofrespect.org/colleges-universities/programs/

Edwards, K. M., Turchik, J. A., Dardis, C. M., Reynolds, N., \& Gidycz, C. A. (2011). Rape Myths: History, Individual and Institutional-Level Presence, and 
Implications for Change. Sex Roles,65(11-12), 761-773. doi:10.1007/s11199-0119943-2

Feild, H. S. (1978). Attitudes toward rape: A comparative analysis of police, rapists, crisis counselors, and citizens. Journal of Personality and Social Psychology,36(2), 156-179. doi:10.1037//0022-3514.36.2.156

Fernandes, M. F., \& Randall, D. M. (1992). The Nature of Social Desirability Response Effects in Ethics Research. Business Ethics Quarterly,2(2), 183. doi: $10.2307 / 3857570$

Field, A. (2009). Discovering Statistics Using SPSS. London: Sage.

Fisher, B. S., Daigle, L. E., \& Cullen, F. T. (2010). Unsafe in the ivory tower: the sexual victimization of college women. Los Angeles: Sage.

Funder, D. C., Levine, J. M., Mackie, D. M., Morf, C. C., Sansone, C., Vazire, S., \& West, S. G. (2013). Improving the Dependability of Research in Personality and Social Psychology. Personality and Social Psychology Review, 18(1), 3-12. doi: $10.1177 / 1088868313507536$

Gates, G. J. (2011). How many people are lesbian, gay, bisexual, and transgender? The Williams Institute.

Giacopassi, D. J., \& Dull, R. T. (1986). Gender and racial differences in the acceptance of rape myths within a college population. Sex Roles, 15(1-2), 63-75. doi:10.1007/bf00287532

Johnson, B. E., Kuck, D. L., \& Schander, P. R. (1997). Rape myth acceptance and sociodemographic characteristics: A multidimensional analysis. Sex Roles, 36(1112), 693-707. 
Katz, J., \& Moore, J. (2013). Bystander Education Training for Campus Sexual Assault Prevention: An Initial Meta-Analysis. Violence and Victims,28(6), 1054-1067. doi:10.1891/0886-6708.vv-d-12-00113

Koss, M. P., Gidycz, C. A., \& Wisniewski, N. (1987). The scope of rape: Incidence and prevalence of sexual aggression and victimization in a national sample of higher education students. Journal of Consulting and Clinical Psychology, 55(2), 162170.

Kruttschnitt, C., Kalsbeek, W. D., \& House, C. C. (2014). Estimating the incidence of rape and sexual assault. Retrieved March, 2017, from https://www.nap.edu/catalog/18605/estimating-the-incidence-of-rape-and-sexualassault

Lonsway, K. A., \& Fitzgerald, L. F. (1995). Attitudinal antecedents of rape myth acceptance: A theoretical and empirical reexamination. Journal of Personality and Social Psychology,68(4), 704-711. doi:10.1037//0022-3514.68.4.704

Lonsway, K. A., Welch, S., \& Fitzgerald, L. F. (2001). Police Training in Sexual Assault Response. Criminal Justice and Behavior,28(6), 695-730. doi:10.1177/009385480102800602

Lonsway, K., \& Fitzgerald, L. (1994). RAPE MYTHS. Psychology Of Women Quarterly, $18(2), 133-164$.

McMahon, S., \& Farmer, G. L. (2011). An Updated Measure for Assessing Subtle Rape Myths. Social Work Research, 35(2), 71-81.

Me Too. (n.d.). Retrieved April, 2018, from https://metoomvmt.org/ 
Osborne, J. W., Costello, A. B., \& Kellow, J. T. (n.d.). Best Practices in Exploratory Factor Analysis. Best Practices in Quantitative Methods,86-99. doi: $10.4135 / 9781412995627 . d 8$

Payne, D. L., Lonsway, K. A., \& Fitzgerald, L. F. (1999). Rape Myth Acceptance: Exploration of Its Structure and Its Measurement Using the Illinois Rape Myth Acceptance Scale. Journal of Research in Personality, 33(1), 27-68.

Proto-Campise, L., Belknap, J., \& Wooldredge, J. (1998). High School Students' Adherence to Rape Myths and the Effectiveness of High School Rape-awareness Programs. Violence Against Women, 4(3), 308-328.

Rau, T. J., Merrill, L. L., Mcwhorter, S. K., Stander, V. A., Thomsen, C. J., Dyslin, C. W., . . Milner, J. S. (2010). Evaluation of a Sexual Assault Education/Prevention Program for Male U.S. Navy Personnel. Military Medicine,175(6), 429-434. doi:10.7205/milmed-d-09-00218

Rau, T. J., Merrill, L. L., Mcwhorter, S. K., Stander, V. A., Thomsen, C. J., Dyslin, C. W., . . Milner, J. S. (2011). Evaluation of a Sexual Assault Education/Prevention Program for Female U.S. Navy Personnel. Military Medicine, 176(10), 1178-1183. doi:10.7205/milmed-d-10-00298

Sable, M. R., Danis, F., Mauzy, D. L., \& Gallagher, S. K. (2006). Barriers to Reporting Sexual Assault for Women and Men: Perspectives of College Students. Journal of American College Health,55(3), 157-162. doi:10.3200/jach.55.3.157-162

Schulze, Corina, \& Koon-Magnin. (2017). Gender, sexual orientation, and rape myth acceptance: Preliminary findings from a sample of primarily LGBQ-identified survey respondents. Violence and Victims, 32(1), 159. 
Shapiro, D. N., Chandler, J., \& Mueller, P. A. (2013). Using Mechanical Turk to Study Clinical Populations. Clinical Psychological Science,1(2), 213-220. doi: $10.1177 / 2167702612469015$

Smith, M., Wilkes, N., \& Bouffard, L. (2016). Rape Myth Adherence Among Campus Law Enforcement Officers. Criminal Justice and Behavior, 43(4), 539-556.

Spohn, R. B. (1993). Social Desirability Correlates for Acceptance of Rape Myth. Psychological Reports,73(3_suppl), 1218-1218. doi:10.2466/pr0.1993.73.3f.1218

Stephens, T., Kamimura, A., Yamawaki, N., Bhattacharya, H., Mo, W., Birkholz, R., Makomenaw, A., \& Olson, L. (2016). Rape Myth Acceptance Among College Students in the United States, Japan, and India. SAGE open.

Szymanski, L. A., Devlin, A. S., Chrisler, J. C., \& Vyse, S. A. (1993). Gender role and attitudes toward rape in male and female college students. Sex Roles,29(1-2), 3757. doi:10.1007/bf00289995

Tabachnick, B. G., \& Fidell, L. S. (2001). Using multivariate statistics. Boston: Allyn and Bacon.

U.S.Cong., Senate - Health, Education, Labor, and Pensions. (2013). Campus Sexual Violence Elimination Act (S. Williams, Author) [Cong. Bill from 113th Congress Cong.].

Vonderhaar, R. L., \& Carmody, D. C. (2015). There Are No "Innocent Victims". Journal of Interpersonal Violence,30(10), 1615-1632. doi:10.1177/0886260514549196 


\section{Appendix A: RMA Survey Items}

Table 1

RMA Survey Items

Sub-factor

AFI When people go to parties wearing revealing clothing, they are asking for trouble

If a person is raped while drunk, they are at least somewhat responsible for letting things get out of control

If a person is sexually "easy", they are eventually going to get into trouble

If a person goes to a room alone with another person at a party, it is their own fault if they get raped

TL A lot of times when a person claims they were raped, they just have emotional problems

A lot of times, people who said they were raped often led the person on and then had regrets

Rape accusations are often used as a way of getting back the accused

A lot of times, people who say they were raped agreed to have sex and then regret it

People who are caught cheating on their significant others sometimes claim it was rape

WRR If a person doesn't physically resist - even if protesting verbally - it can't be considered rape

If the accused "rapist" doesn't have a weapon, you can't really call it rape

If a person does not verbally say "no", they can't really claim rape

If a person didn't physically fight back, you can't really say it was rape

DMT When people rape, it is usually because of their strong desire for sex

Rape happens when a person's sex drive is out of control

People don't usually intend to force sex on a person, but sometimes they get too sexually carried away

If a person is drunk, they may unintentionally rape someone

DMT-I If both people are drunk, it can't be rape

It shouldn't be considered rape if the accused was drunk and didn't know what they were doing

*AFI: Asked for it, TL: They lied, WRR: Wasn't really rape, DMT: Didn't mean to, DMT-I: Didn't mean to - intoxicated

*All items are combined to form a single factor scale, as well.

*Items come from an adjusted version of the Updated Illinois Rape Myth Acceptance scale (McMahon and Farmer, 2011) 


\section{Appendix B: Video Script}

Treatment video, script.

According to the Department of Justice, the federal definition of sexual assault is any type of sexual contact or behavior that occurs without the explicit consent of the recipient. Falling under the definition of sexual assault are sexual activities including forced sexual intercourse, forcible sodomy, child molestation, incest, fondling, and attempted rape. It is important to note that not all sexual assault comes in the form of rape, but rape is a type of sexual assault (2017). Loosely put, the current federal definition of rape is the penetration of any body part without the consent of the victim. This includes oral penetration. As of 2012, rape is also considered a gender-neutral crime. Meaning that men, women, non-binary individuals, and other positions on the gender spectrum, can all be perpetrators or victims of rape.

An important component to understanding rape is understanding consent. In this context, consent is the ability for an individual to make a decision about engaging in a sexual activity. Some examples where consent cannot be given are if drugs or alcohol have been consumed. Being underage by state or federal guidelines also means an individual cannot consent. Finally, consent is not assumed by lack of physical resistance or fighting back by an individual (Department of Justice, 2017). Simply put, if a person cannot consent to a sexual activity for any of these reasons, then it can be legally classified as rape.

Though this is the current legal definition of rape, there seems to be a lack of a collective social definition. This simply means that what different individuals consider rape varies greatly throughout society. But why is this so? Well, the lack of a collective social definition is largely supported by the concept of rape myths and how much different people believe them. Rape myths refer to the culturally prescribed and largely inaccurate, though widely believed, perceptions that people have about sexual violence, its perpetrators, and its victims (Payne, Lonsway, \& Fitzgerald, p. 22, 1999). These are often driven by stereotypes and misunderstanding. Rape myths have the effect of directly or indirectly removing the blame of rape from the person who committed the act, instead placing it on the person who was targeted by the act.

But what are some examples of common rape myths and how do we know they are not true? To ensure a firm understanding, we will now review six common rape myths and debunk them with research.

Myth one. Rape is driven purely by sexual desire.

Though desire for sex may be a component in acquaintance rape, (which is when the victim knows their rapist), sexual desire is often not the driving force behind why a rape occurs. Research has shown that rapists are often more concerned with asserting power, control, and dominance over victims than they are about meeting a natural desire for sex (Chiroro, Bohner, Viki, \& Jarvis, 2004). It should be noted that sexual desire could be an initial reason for an individual to act in a manner that may lead to acquaintance rape, but it is likely not the overall reason. For example, if an individual wants to engage in a sexual activity with someone they know and the person does not give consent, the individual who wanted to have sex could react in a negative way which shifts their desire for sex to a desire to express the characteristics previously mentioned, such as power and dominance. This desire for to express could impact the individual to force sex upon the other person.

The myth that rape is driven by sexual desire is reinforced by other ideas held by society, such as if the victim acted flirtatiously toward their rapist, if the victim initiated contact first but did not give consent for further contact, or if the victim was dressed in a way that is considered "provocative".

Considering nearly $50 \%$ of reported rapes have been said to occur during times the victim was sleeping or doing something else in their home, many of these appear to be false assumptions (RAAIN, Scope of the Problem: Statistics). Further in a study conducted on stranger rapists, only 7\% reported that the physical sexual appearance of their victim had an impact on their selection process (Beauregard, Rossmo, \& Proulx, 
2007). Given this information it may be safe to say that the myth sexual desire drives rape, is in fact, just a myth.

Myth two. Rape is mostly committed by strangers in dark, unfamiliar, spaces. Though this is what TV and movie media have told us, victim reports show this generally is not true. In fact, according to a 2015 study, 7 out 10 survivors reported they were victimized by someone they knew, such as a spouse, partner, family member, or friend (RAAIN, Perpetrators of Sexual Violence: Statistics). Further, these reports have shown that these rapes occurred in a familiar place. With $55 \%$ of the rapes happening in the victim's home, and only $25 \%$ occurring in public spaces aside from school or work. So again, given this information, it is safe to say, this myth is false.

Myth Three. If a victim does not physically fight back, it cannot be considered rape. Additionally, if there are no marks or bruises left on the survivor, it cannot be rape.

Given the legal definition noted before, we already know that victims do not have to have physically resist or fight back to legally be considered rape. But many may think fighting back is the only logical thing to do when threatened, opening the question of why the legal definition doesn't require resistance. This is largely because psychology research has established the theory of fight, flight, or freeze, when people are feeling threatened.

Flight, would be if the victim runs away. Often this is not an option.

Fight would be if the victim actively fights their rapist. This is may not occur out of fear for further harm. Further, because of this fear, a reaction referred to as tonic immobility could occur in the body, which potentially causes victims to freeze as a defense mechanism (Abrams, Carleton, Taylor, \& Asmundson, 2009).

Regarding the concept of survivors needing to have bruises or marks, this may be flawed thinking because an assault does not have to be directly violent, even if it is a violent crime because rapists can exert power over a person without using physical violence.

Further, threat via weapon during rape is also rather uncommon. Research has suggested only about $11 \%$ of rapists used a physical weapon during an attack. In this sense, fear is the weapon (RAAIN, Perpetrators of Sexual Violence: Statistics).

Given these two circumstances, if a rapist doesn't have to use extreme physical force or weapons on a victim, and if a victim has the behavioral response of "freeze", this could help explain why many survivors do not have extensive marks or bruises. Given this information, we can effectively say that the myth of needing to fight back or have bruises in order for it to be rape is a false.

Myth four. Rape is a trivial event, meaning it is not a big deal for survivors.

Studies have shown that survivors can endure a variety of both long and short-term effects. Some of these includes physical pain, nausea, headaches, unwanted pregnancies, STDs, depression, suicide ideation, eating and panic disorders, and engagement in future risky behavior. Further, these impacts do not occur in just a small number of survivors. $81 \%$ of women and $35 \%$ of men experienced short or long-term effects after an event occurred (NISVS, 2010). Given this information, we can confirm that "rape is a trivial event" is false.

Myth five. There are a lot of false accusations of rape, or, a lot of survivors are lying about rape because they feel guilty or want revenge on the person they are accusing. 
Though media may show this happening with high profile cases involving celebrities and athletes, the actual false report rate is estimated to be pretty low - between $2 \%$ and $10 \%$. This can be compared to the average $2 \%$ of false reporting for all crimes according to the Uniform Crime Report (NSRVC, 2012).

Simply put, the myth the many rape accusations are false, is false.

Finally, myth six. Rape is a deviant event, meaning it doesn't happen that often or to that many people.

Though generating accurate estimates of rape is difficult due to varying definitions and low reporting, where the majority of sexual assaults, an estimated $63 \%$, are never reported to the police, estimated rape rates do exist (Rennison, 2002).

Some of these American estimates include completed or attempted rape on 1 in 5 women from the general population, and 1 in 71 men in the general population (Black et al., 2011). The estimate for college women is even higher, with an estimated 1 in 4 completed or attempted rape). (Campus Climate Survey on Sexual Assault and Sexual, 2015; Koss et al.,1987).

So, given the estimates of underreporting in conjunction with the occurrence estimates, we can consider the myth that rape is deviant, false.

So rape is definitely occurring. But why is it so under-reported?

For one, many survivors know their attacker. Because of this, they may fear further repercussions from the person that raped them, or people close to that person, if they come forward with a rape accusation. There is also the issue of society as a whole though.

Society shames and guilt's victims through rape myths such as the six reviewed here.

As explained, rape myths move guilt from the rapist, onto the survivor.

According to studies interviewing sexual offenders, this is a tactic that sexual offenders themselves use to justify their actions (Meloy \& Miller, 2011; ). Because of this, and because society blames survivors through rape myths, many survivors also blame themselves.

Further, these myths do not exist in a vacuum, meaning that evidence of rape myths can also be found in the legal system (since the legal system is also comprised of individuals influenced by society) (Edwards, Turchik, Dardis, Reynolds \& Gidycz, 2011). This can lead to bias against victims at with police, attorneys, juries, judges, and any encounters within the legal process.

If survivors feel reporting their crime will generate more backlash from people they know, or that no one will believe them, even within the legal system, it is then clear why this may be such an underreported crime. It is also clear why understanding rape myths and debunking important, if we want justice for, and to help people who were victimized by a sexual offender.

\section{References}

Abrams, M. P., Carleton, R. N., Taylor, S., \& Asmundson, G. J. (2009). Human tonic immobility: measurement and correlates. Depression and Anxiety. doi:10.1002/da.20462

An Updated Definition of Rape. (2012, January 06). Retrieved October 12, 2017, from https://www.justice.gov/archives/opa/blog/updated-definition-rape

Beauregard, E., Rossmo, D., \& Proulx, K. (2007). A Descriptive Model of the Hunting Process of Serial Sex Offenders: A Rational Choice Perspective. Journal of Family Violence, 22(6), 449-463. 
Black, M.C., Basile, K.C., Breiding, M.J., Smith, S.G., Walters, M.L., Merrick, M.T., Chen, J., \& Stevens, M.R. (2011). The National Intimate Partner and Sexual Violence Survey (NISVS): 2010 Summary Report. Atlanta, GA: National Center for Injury Prevention and Control, Centers for Disease Control and Prevention.

Cantor, D., Fisher, B., Chibnall, S., Townsend, R., Lee, H., Bruce, C., \& Thomas, G. (2015, September 21). AAU Climate Survey on Sexual Assault and Sexual Misconduct (2015). Retrieved from https://www.aau.edu/key-issues/aau-climate-survey-sexual-assault-and-sexual-misconduct-2015

Chiroro, P., Bohner, G., Viki, G. T., \& Jarvis, C. I. (2004). Rape Myth Acceptance and Rape Proclivity. Journal of Interpersonal Violence, 19(4), 427-442. doi:10.1177/0886260503262081

Edwards, K. M., Turchik, J. A., Dardis, C. M., Reynolds, N., \& Gidycz, C. A. (2011). Rape Myths: History, Individual and Institutional-Level Presence, and Implications for Change. Sex Roles,65(11-12), 761-773. doi:10.1007/s11199-011-9943-2

Koss, M. P., Gidycz, C. A., \& Wisniewski, N. (1987). The scope of rape: Incidence and prevalence of sexual aggression and victimization in a national sample of higher education students. Journal of Consulting and Clinical Psychology, 55(2), 162-170.

Meloy, M. L., \& Miller, S. L. (2011). The victimization of women: law, policies, and politics. New York: Oxford University Press.

Payne, D. L., Lonsway, K. A., \& Fitzgerald, L. F. (1999). Rape Myth Acceptance: Exploration of Its Structure and Its Measurement Using the Illinois Rape Myth Acceptance

Perpetrators of Sexual Violence: Statisics. (n.d.). Retrieved October 17, 2017, from https://www.rainn.org/statistics/perpetrators-sexual-violence

Rennison, C. A. (2002). Rape and sexual assault: Reporting to police and medical attention, 1992-2000 [NCJ 194530]. PsycEXTRA Dataset. doi:10.1037/e387542004-001

Scope of the Problem: Statistics. (n.d.). Retrieved October 17, 2017, from https://www.rainn.org/statistics/scope-problem

Sexual Assault. (n.d.). Retrieved October 12, 2017, from https://www.justice.gov/ovw/sexual-assault 


\section{Appendix C: Changes in Measure Post Intervention}

Table 3

Changes in Measure Post Intervention

\begin{tabular}{|c|c|c|c|c|c|c|c|c|}
\hline Scale & Group & \# of items & Med & Mean & $S D$ & $t$ & $p$ & $r$ \\
\hline \multirow[t]{2}{*}{ FULL } & Treatment & 19 & -0.26 & -0.38 & -0.43 & -5.94 & $.000 * *$ & -0.51 \\
\hline & Control & & -0.05 & -0.07 & 0.18 & -3.46 & $.001 *$ & -0.3 \\
\hline \multirow[t]{2}{*}{ TL } & Treatment & 5 & -0.2 & -0.36 & 0.53 & -5.22 & $.000 * *$ & -0.45 \\
\hline & Control & & 0 & -0.03 & 0.39 & -0.62 & 0.54 & -0.05 \\
\hline \multirow[t]{2}{*}{ AFI } & Treatment & 4 & -0.25 & -0.37 & 0.66 & -4.08 & $.000 * *$ & -0.35 \\
\hline & Control & & 0 & -0.1 & 0.27 & -2.97 & $.003 *$ & -0.25 \\
\hline \multirow[t]{2}{*}{ DMT } & Treatment & 4 & -0.33 & -0.56 & 0.81 & -4.94 & $.000 * *$ & -0.42 \\
\hline & Control & & 0 & -0.03 & 0.49 & -1.53 & 0.13 & -0.13 \\
\hline \multirow[t]{2}{*}{ DMT - I } & Treatment & 2 & -0.33 & -0.55 & 0.64 & -5.43 & $.000^{* *} *$ & -0.46 \\
\hline & Control & & -0.25 & -0.31 & 0.54 & -4.25 & $.000 * *$ & -0.36 \\
\hline \multirow[t]{2}{*}{ WRR } & Treatment & 5 & 0 & -0.24 & 0.43 & -4.14 & $.031 *$ & -0.35 \\
\hline & Control & & 0 & -0.07 & 0.39 & -2.15 & $.000 * *$ & -0.18 \\
\hline
\end{tabular}

$* p<.05 . * * p<.001$ 


\section{Appendix D: RMA Score Differences by Demographic, Full Scale}

Table 4

RMA Score Differences by Demographic, Full Scale

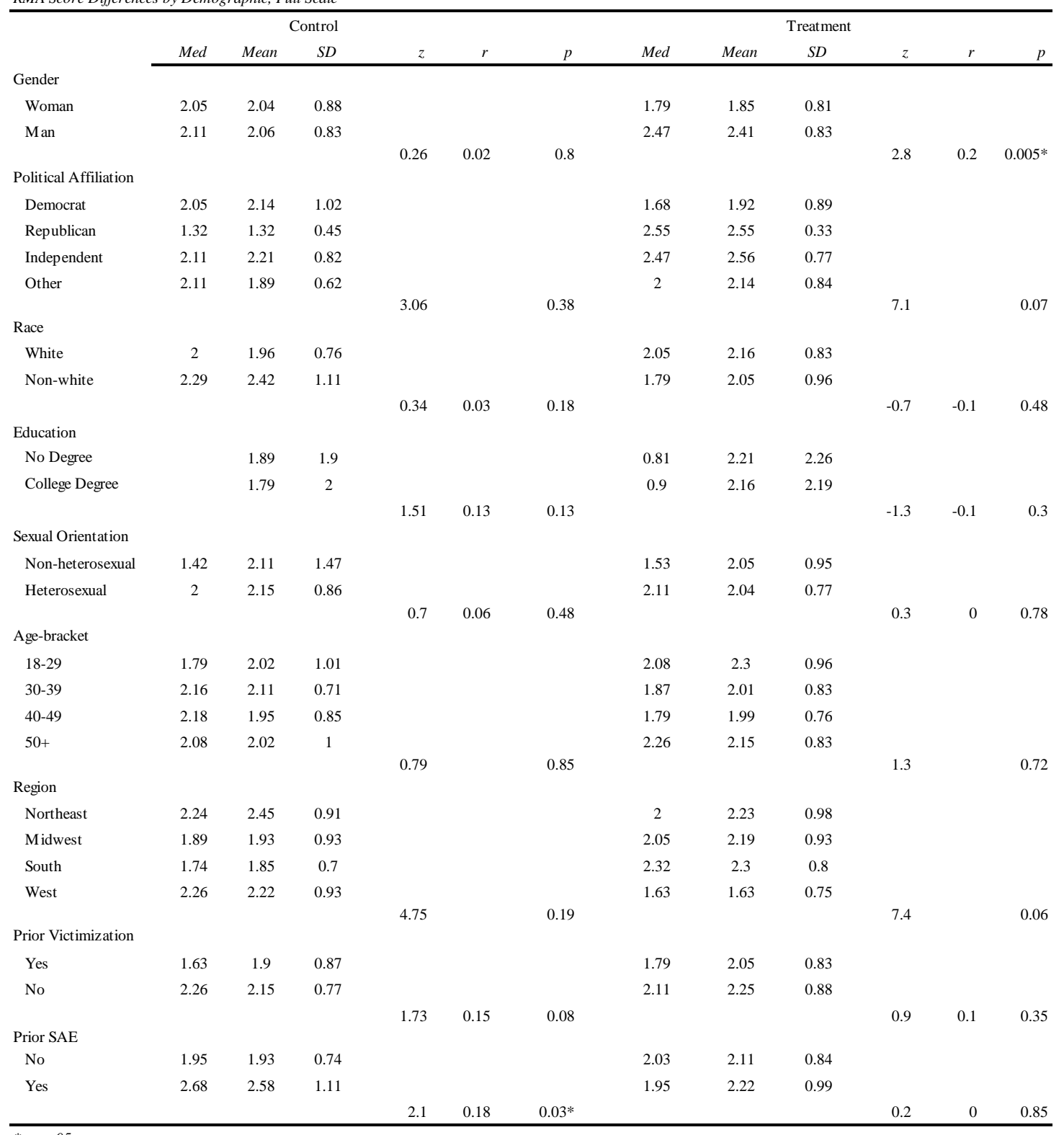

$* p<.05$

*SAE: sexual assault education 


\section{Appendix E: RMA Score Differences by Demographic, AFI}

Table 5

RMA Score Differences by Demographic, AFI

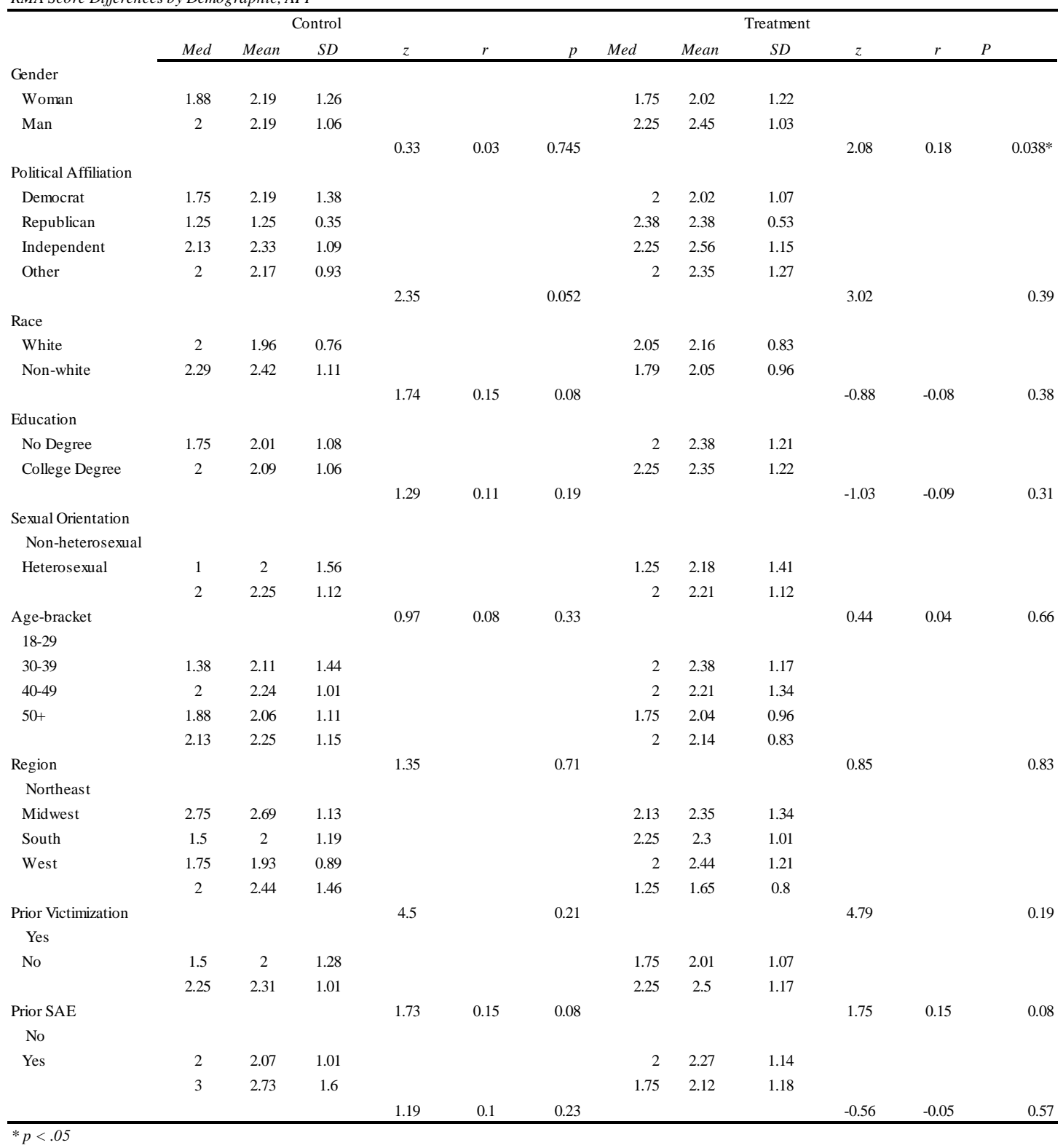




\section{Appendix F: RMA Score Differences by Demographic, TL}

Table 6

RMA Score Differences by Demographic, TL

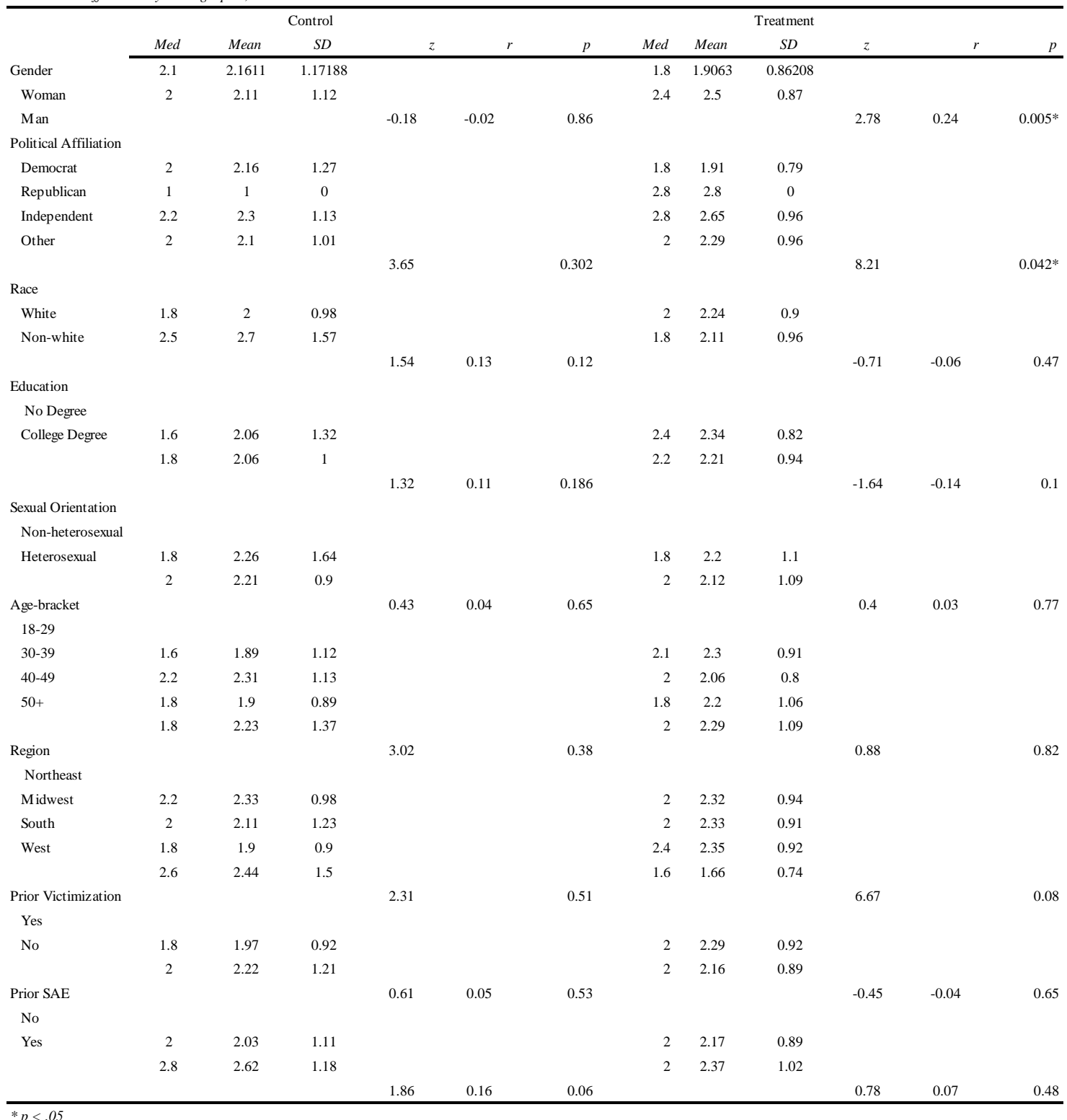




\section{Appendix G:}

\section{RMA Score Differences by Demographic, WRR}

Table 7

RMA Score Differences by Demographic, WRR

\begin{tabular}{|c|c|c|c|c|c|c|c|c|c|c|c|c|}
\hline & & & ontrol & & & & & & eatmen & & & \\
\hline & Med & Mean & $S D$ & $z$ & $r$ & $p$ & Med & Mean & $S D$ & $z$ & $r$ & $p$ \\
\hline \multicolumn{13}{|l|}{ Gender } \\
\hline Woman & 1.25 & 1.68 & 0.84 & & & & 1.25 & 1.52 & 0.75 & & & \\
\hline \multirow[t]{2}{*}{ Man } & 1.5 & 1.72 & 0.85 & & & & 1.75 & 1.86 & 0.89 & & & \\
\hline & & & & 0.49 & 0.04 & 0.622 & & & & 2.04 & 0.17 & 0.041 * \\
\hline \multicolumn{13}{|l|}{ Political Affiliation } \\
\hline Democrat & 1.75 & 1.91 & 1.03 & & & & 1 & 1.48 & 0.88 & & & \\
\hline Republican & 1 & 1 & 0 & & & & 2 & 2 & 0 & & & \\
\hline Independent & 1.38 & 1.8 & 0.81 & & & & 2 & 2.23 & 0.93 & & & \\
\hline \multirow[t]{2}{*}{ Other } & 1.25 & 1.46 & 0.54 & & & & 1.5 & 1.62 & 0.59 & & & \\
\hline & & & & 5.97 & & 0.113 & & & & 12.67 & & $0.005 *$ \\
\hline \multicolumn{13}{|l|}{ Race } \\
\hline White & 1.25 & 1.6 & 0.69 & & & & 1.5 & 1.77 & 0.9 & & & \\
\hline \multirow[t]{2}{*}{ Non-white } & 1.88 & 2.13 & 1.24 & & & & 1.25 & 1.49 & 0.6 & & & \\
\hline & & & & 1.54 & 0.13 & 0.123 & & & & -0.71 & -0.06 & 0.48 \\
\hline \multicolumn{13}{|l|}{ Education } \\
\hline No Degree & 1 & 1.62 & 0.83 & & & & 1.5 & 1.75 & 0.75 & & & \\
\hline \multirow[t]{2}{*}{ College Degree } & 1.25 & 1.63 & 0.92 & & & & 1.5 & 1.78 & 0.86 & & & \\
\hline & & & & 1.37 & 0.12 & 0.169 & & & & 1.32 & 0.11 & 1.85 \\
\hline \multicolumn{13}{|l|}{ Sexual Orientation } \\
\hline Non-heterosexual & 1 & 1.93 & 1.56 & & & & 1.25 & 1.32 & 0.4 & & & \\
\hline \multirow[t]{2}{*}{ Heterosexual } & 1.5 & 1.74 & 0.86 & & & & 1.5 & 1.68 & 0.74 & & & \\
\hline & & & & 0.09 & 0.01 & 0.67 & & & & 1.21 & 0.1 & 0.22 \\
\hline \multicolumn{13}{|l|}{ Age-bracket } \\
\hline $18-29$ & 1.25 & 1.71 & 1.04 & & & & 1.5 & 1.83 & 1.07 & & & \\
\hline $30-39$ & 1.5 & 1.73 & 0.77 & & & & 1.5 & 1.51 & 0.53 & & & \\
\hline $40-49$ & 1.88 & 1.72 & 0.66 & & & & 1.38 & 1.69 & 0.8 & & & \\
\hline \multirow[t]{2}{*}{$50+$} & 1.13 & 1.6 & 0.86 & & & & 1.75 & 1.71 & 0.62 & & & \\
\hline & & & & 0.94 & & 0.81 & & & & 0.9 & & 0.82 \\
\hline \multicolumn{13}{|l|}{ Region } \\
\hline Northeast & 1.88 & 2.15 & 1.19 & & & & 1.88 & 1.98 & 1.09 & & & \\
\hline Midwest & 1 & 1.54 & 0.84 & & & & 1.25 & 1.7 & 0.89 & & & \\
\hline South & 1.25 & 1.54 & 0.62 & & & & 1.75 & 1.77 & 0.84 & & & \\
\hline \multirow[t]{2}{*}{ West } & 1.75 & 1.79 & 0.84 & & & & 1 & 1.29 & 0.35 & & & \\
\hline & & & & 4.34 & & 0.22 & & & & 5 & & 0.17 \\
\hline \multicolumn{13}{|l|}{ Prior Victimization } \\
\hline Yes & 1 & 1.59 & 0.96 & & & & 1.5 & 1.62 & 0.79 & & & \\
\hline \multirow[t]{2}{*}{ No } & 1.5 & 1.77 & 0.71 & & & & 1.75 & 1.78 & 0.88 & & & \\
\hline & & & & 2.06 & 0.18 & $0.04 *$ & & & & 0.88 & 0.08 & 0.38 \\
\hline \multicolumn{13}{|l|}{ Prior SAE } \\
\hline No & 1.25 & 1.63 & 0.72 & & & & 1.5 & 1.6 & 0.7 & & & \\
\hline \multirow[t]{2}{*}{ Yes } & 2 & 2.04 & 1.23 & & & & 1.75 & 2.06 & 1.2 & & & \\
\hline & & & & 0.93 & 0.08 & 0.35 & & & & 1.31 & 0.11 & 0.19 \\
\hline
\end{tabular}




\section{Appendix H: RMA Score Differences by Demographic, DMT}

Table 8

RMA Score Differences by Demographic, DMT

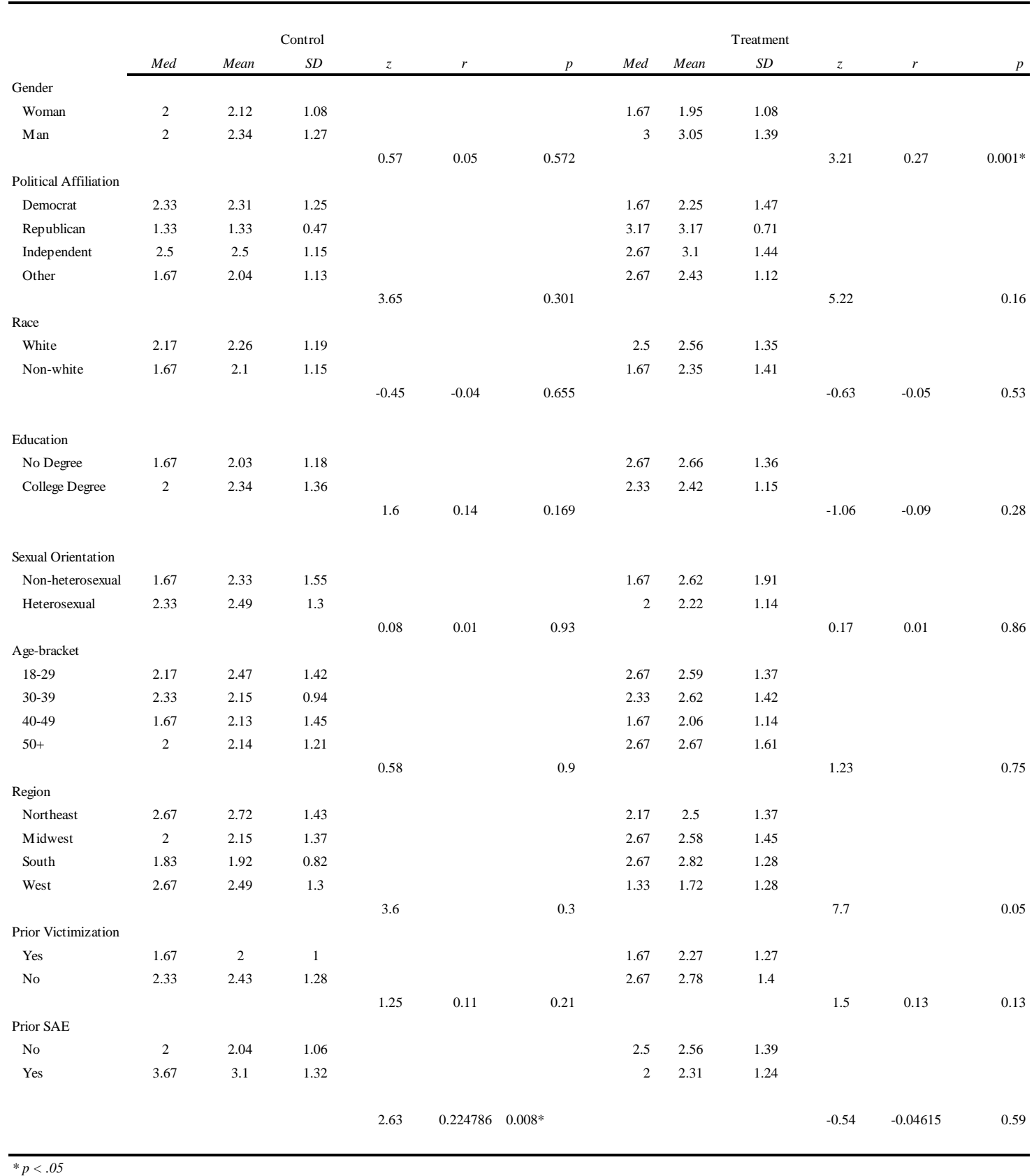




\section{Appendix I: RMA Score Differences by Demographic, DMT-I}

Table 9

RMA Score Differences by Demographic, DMT-I

\begin{tabular}{|c|c|c|c|c|c|c|c|c|c|c|c|c|}
\hline & & & ontrol & & & & & & & eatmen & & \\
\hline & Med & Mean & $S D$ & $z$ & $r$ & $p$ & Med & Mean & $S D$ & $z$ & $r$ & $p$ \\
\hline \multicolumn{13}{|l|}{ Gender } \\
\hline Woman & 2 & 2.04 & 0.96 & & & & 2 & 1.86 & 0.83 & & & \\
\hline \multirow[t]{2}{*}{ Man } & 2 & 1.97 & 0.82 & & & & 2 & 2.31 & 0.97 & & & \\
\hline & & & & -0.16 & -0.01 & 0.873 & & & & 1.78 & 0.15 & 0.07 \\
\hline \multicolumn{13}{|l|}{ Political Affiliation } \\
\hline Democrat & 2.33 & 2.21 & 0.91 & & & & 2 & 2.03 & 1.13 & & & \\
\hline Republican & 2.33 & 2.33 & 1.89 & & & & 2.5 & 2.5 & 0.71 & & & \\
\hline Independent & 2 & 2.19 & 0.95 & & & & 2.33 & 2.31 & 0.46 & & & \\
\hline \multirow[t]{2}{*}{ Other } & 1.67 & 1.63 & 0.65 & & & & 2 & 2 & 0.86 & & & \\
\hline & & & & 6.84 & & 0.077 & & & & 2.72 & & 0.44 \\
\hline \multicolumn{13}{|l|}{ Race } \\
\hline White & 2 & 1.96 & 0.86 & & & & 2 & 2.02 & 0.86 & & & \\
\hline \multirow[t]{2}{*}{ Non-white } & 2 & 2.19 & 1.01 & & & & 2 & 2.29 & 1.09 & & & \\
\hline & & & & 0.72 & 0.06 & 0.477 & & & & 6.89 & 0.59 & 0.49 \\
\hline \multicolumn{13}{|l|}{ Education } \\
\hline No Degree & 1.67 & 1.74 & 0.79 & & & & 2.17 & 2.23 & 0.85 & & & \\
\hline \multirow[t]{2}{*}{ College Degree } & 2 & 1.95 & 1 & & & & 2.33 & 2.25 & 0.91 & & & \\
\hline & & & & 2.42 & 0.21 & $0.015^{*}$ & & & & -1.67 & -0.14 & 0.09 \\
\hline \multicolumn{13}{|l|}{ Sexual Orientation } \\
\hline Non-heterosexual & 1.67 & 2.05 & 1.27 & & & & 2.33 & 2.05 & 0.8 & & & \\
\hline \multirow[t]{2}{*}{ Heterosexual } & 2 & 2.1 & 0.94 & & & & 2 & 2 & 0.85 & & & \\
\hline & & & & 0.8 & 0.07 & 0.8 & & & & -0.2 & -0.02 & 0.84 \\
\hline \multicolumn{13}{|l|}{ Age-bracket } \\
\hline $18-29$ & 2 & 2.05 & 0.98 & & & & 2.5 & 2.5 & 1.06 & & & \\
\hline $30-39$ & 1.83 & 2.05 & 0.78 & & & & 1.33 & 1.7 & 0.76 & & & \\
\hline $40-49$ & 2.17 & 2 & 1.02 & & & & 2 & 1.92 & 0.62 & & & \\
\hline \multirow[t]{2}{*}{$50+$} & 1.5 & 1.81 & 0.99 & & & & 2 & 2 & 0.77 & & & \\
\hline & & & & 1.29 & & 0.73 & & & & 8.02 & & 0.05 \\
\hline \multicolumn{13}{|l|}{ Region } \\
\hline Northeast & 2.33 & 2.47 & 0.83 & & & & 2 & 1.97 & 0.84 & & & \\
\hline Midwest & 1.67 & 1.82 & 0.91 & & & & 2.33 & 2.09 & 0.99 & & & \\
\hline South & 1.67 & 1.99 & 0.96 & & & & 2 & 2.2 & 0.8 & & & \\
\hline \multirow[t]{2}{*}{ West } & 2 & 1.84 & 0.71 & & & & 1.33 & 1.92 & 1.24 & & & \\
\hline & & & & 5.28 & & 0.15 & & & & 2.35 & & 0.5 \\
\hline \multicolumn{13}{|l|}{ Prior Victimization } \\
\hline Yes & 1.67 & 1.94 & 1.01 & & & & 2 & 2.08 & 0.83 & & & \\
\hline \multirow[t]{2}{*}{ No } & 2 & 2.03 & 0.72 & & & & 2 & 2.14 & 1.01 & & & \\
\hline & & & & 0.82 & 0.07 & & & & & -0.11 & -0.01 & 0.91 \\
\hline \multicolumn{13}{|l|}{ Prior SAE } \\
\hline No & 1.67 & 1.89 & 0.84 & & & & 2 & 2.06 & 0.9 & & & \\
\hline \multirow[t]{2}{*}{ Yes } & 2.33 & 2.54 & 0.92 & & & & 2.33 & 2.23 & 1.05 & & & \\
\hline & & & & 2.5 & 0.21 & $0.01 *$ & & & & 0.54 & 0.05 & 0.58 \\
\hline
\end{tabular}




\section{Appendix J: Correlations Between Age and RMA, Control Group}

Table 10

Correlations Between Age and RMA, Control Group

\begin{tabular}{lcccccc} 
Scale & Full & Asked For It & They Lied & Wasn't Really Rape & Didn't Mean To & Didn't Mean To - Intoxicated \\
\cline { 2 - 6 } Correlation Coefficient & 0.1 & 0.12 & 0.15 & 0.05 & 0.02 & 0.03 \\
Significance (2-tailed) & 0.41 & 0.33 & 0.21 & 0.7 & 0.85 & 0.83 \\
$\mathrm{~N}$ & 72 & 72 & 72 & 72 & 72 & 72 \\
\hline
\end{tabular}

* Spearman's Rho 
Appendix K: Correlations Between Age and RMA, Treatment Group

Table 11

Correlations Between Age and RMA, Treatment Group

Scale

Correlation Coefficient

Significance (2-tailed)

$\mathrm{N}$

\begin{tabular}{cccccc} 
Full & Asked For It & They Lied & Wasn't Really Rape & Didn't Mean To & Didn't Mean To - Intoxicated \\
\hline-0.04 & -0.04 & -0.04 & 0.03 & -0.03 & -0.17 \\
0.73 & 0.77 & 0.77 & 0.79 & 0.82 & 0.17 \\
65 & 65 & 65 & 65 & 65 & 65
\end{tabular}

* Spearman's Rho 